\title{
Seismogenic deformation field in the Mojave block and implications for tectonics of the eastern California shear zone
}

\author{
Jeffrey R. Unruh \\ William Lettis \& Associates, Inc., Walnut Creek, Califomia
}

Robert J. Twiss

Department of Geology, University of California, Davis

Egill Hauksson

Seismological Laboratory, Califomia Institute of Technology, Pasadena

\begin{abstract}
From the aftershocks of the 1992 Landers earthquake, we infer the orientation of the principal strain rate axes $\left(d_{1}>d_{2}>d_{3} ; d_{1}\right.$ lengthening), their relative magnitude, and the relative spin of fault blocks by using a micropolar continuum model to invert the seismic $P$ and $T$ axes. The seismogenic deformation is consistent with the geodetic measurements of the coseismic displacement and with the secular deformation of the central Mojave block. Regionally, the aftershock data define two major domains within the central Mojave block: (1) the western Mojave block, including the San Bernardino Mountains and the epicentral area of the Big Bear earthquake, which is characterized by E-W $d_{1}$ (lengthening) and N-S $d_{3}$ (shortening); and (2) the central Mojave block, including the Landers surface rupture zone, which is characterized by NW-SE $d_{1}$ and NE-SW $d_{3}$. Inversion for the principal strain axes of geodetically measured coseismic displacements across the Big Bear and Landers seismogenic zones gives results similar to the aftershock inversions for those areas, indicating that the aftershocks accommodate a deformation similar to the main rupture and do not reflect elastic rebound or residual stresses. The background seismicity for 1981 to 1991 shows the same characteristic $d_{1}$ and $d_{3}$ orientations for the two domains, indicating that the secular seismogenic strain has the same regional geometry as the 1992 coseismic deformation. The micropolar inversion also provides values of the relative vorticity parameter $W$, which reflects a difference between the vorticity of a shearing continuum and the vorticity of fault-bounded blocks rotating within tabular seismogenic shear zones. The observed fault geometry along the Kickapoo fault suggests a pinned-block model for the local block rotation that is consistent with the values of $W$ obtained from our inversions. We interpret the regional NW-SE orientation of $d_{1}$ in the central Mojave block to be characteristic of the dextral eastern California shear zone, which transfers approximately 22\% of the Pacific-North American plate motion from the San Andreas system to the Walker Lane Belt in eastern California. Our results and geodetic determinations of the secular shear strain in the central Mojave block indicate that the locus of NW dextral shear generally lies between the San Bernardino Mountains and the Pisgah fault.
\end{abstract}

\section{Introduction}

The $M_{w} 7.3$ June 1992 Landers earthquake deformed a large area of the Mojave block, a roughly triangular region in southern California bounded by the San Andreas fault on the southwest and by the Garlock fault on the northwest (Figure 1). The central Mojave block is traversed by the eastern California shear zone, a north to northwest trending zone of distributed late Cenozoic strike-slip faulting [Dokka and Travis, 1990; Savage et al., 1990]. The 80-km-long system of strike-slip faults that ruptured during the 1992 Landers earthquake (Figure 1) is located within the eastern California shear zone. Dokka and Travis [1990] proposed that dextral strike-slip faulting in the eastern California shear zone may accommodate a

Copyright 1996 by the Americal Geophysical Union.

Paper number 95JB03040.

0148-0227/96/95JB-03040\$05.00 component of Pacific/North American plate motion, and subsequent geodetic analyses indicate that the integrated NW dextral shear across the region may be as much as $12 \mathrm{~mm} / \mathrm{yr}$ [Sauber et al., 1994]. The eastern California shear zone links the San Andreas fault system in southern California with the southern Walker Lane belt, a northwest trending zone of distributed strike-slip and normal faulting east of the Sierra Nevada [Wright, 1976; Stewart, 1988; Dixon et al., 1995]. Very Long Baseline Interferometry (VLBI) studies show that the Sierra Nevada presently is moving approximately 11 $\mathrm{mm} / \mathrm{yr}$ northwest with respect to stable North America [Argus and Gordon, 1991; Dixon et al., 1995]. This motion must be accommodated east of the Sierra Nevada, and it is likely that a major portion is taken up in shear within the Walker Lane Belt, which is a northern continuation of the eastern California shear zone. The motion determined by VLBI is comparable to the integrated rate of NW dextral shear across the eastern California shear zone [Sauber et al., 1994], even though the motion in the latter study is not referenced to stable 


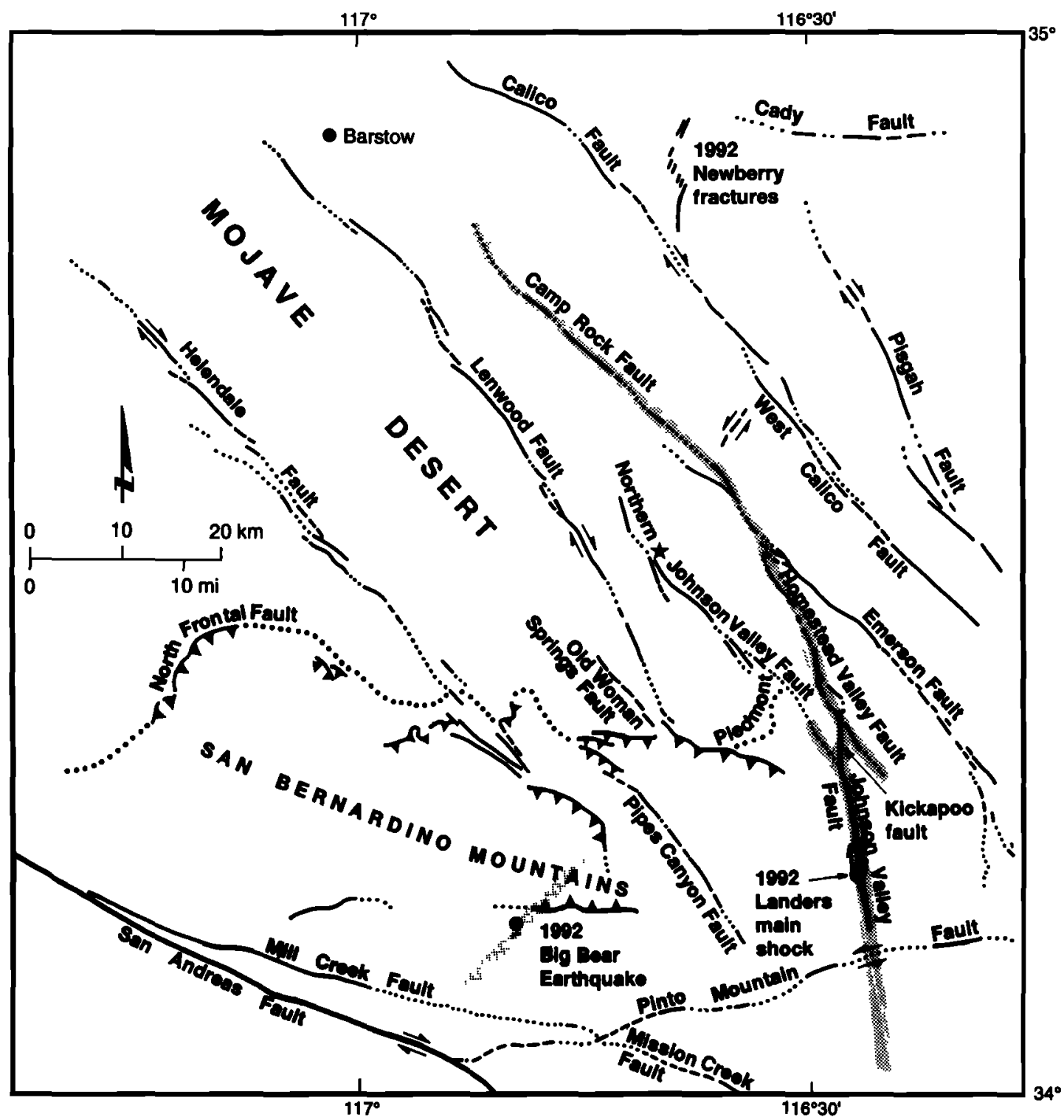

Figure 1. Major faults in the central Mojave desert. Stippled lines show locations of major faults that ruptured during the 1992 Landers earthquake. The northeast striking fault that produced the Big Bear earthquake is blind and known only from the locations of aftershocks.

North America. These relations indicate that the eastern California shear zone and Walker Lane belt together may accommodate a large portion of the approximately $22-25 \%$ of Pacific/North American plate motion that occurs east of the Sierra Nevada [Dokka and Travis, 1990; Dixon et al., 1995].

To better understand the influence of the eastern California shear zone on the deformation of the Mojave block, we use aftershocks of the Landers earthquake sequence to analyze the kinematics of local and regional coseismic deformation. We adopt a new approach for evaluating the coseismic deformation by using the kinematic description of a micropolar continuum [Eringen, 1964, 1966, 1967] as the basis for inverting seismic $P$ and $T$ axes from aftershock focal mechanisms and by interpreting the $P$ and $T$ axes to be principal strain rate axes rather than the more usual interpretation that they are principal stress axes. We solve for the orientations of the principal strain rates $d_{k}$ (deformation rates), their relative magnitudes as defined by the deformation rate parameter $D$, and the magnitude of the relative vorticity parameter $W$ of blocks in the seismogenic shear zone [Twiss et al., 1991, 1993]. (We define $D$ and $W$ in more detail in the following section.) Because the principal strain rates are in essence the principal incremental strains, which approximate the principal infinitesimal strains, we can compare the inferred seismogenic strain rate field directly to the coseismic strains determined by inversion of geodetic data, and we can infer constraints on the kinematics of block rotations within seismogenic shear zones.

Using this approach, we seek (1) to test the hypothesis that aftershock focal mechanisms can be used directly to evaluate and map the seismogenic deformation field; (2) to test the hypothesis that we can infer the kinematics of faulting, including an objective relative rate of fault block rotation within seismogenic shear zones, by solving the micropolar inverse problem using focal mechanism data; and (3) to 
interpret the tectonic significance of the Landers earthquake for accommodating distributed Pacific/North American plate motion in the eastern California shear zone.

In the next three sections, successively, we summarize the micropolar theory that forms the basis of our inversion of focal mechanism solutions, we summarize the arguments that the inversion provides information about the normalized strain rates rather than normalized stresses, and we review the techniques that we used in analyzing the data. The subsequent three sections present the main results of our analysis, including our inversions of focal mechanism and geodetic data; the seismic and structural evidence for block rotations; and an interpretation of the seismotectonics of the eastern California shear zone. Our conclusions are summarized in the last section, and two appendices give details of our inversion procedure and results of a sensitivity analysis of the misfit of the data to the values of the model parameters.

\section{Summary of Micropolar Theory}

We use micropolar kinematic theory to invert the seismic $P$ and $T$ axes in order to include the effects of rigid fault block rotations in the description of the deformation. The use of micropolar continuum theory to understand the effects of block rotations on shear plane/slip direction patterns is developed by Twiss et al. [1991], and the theoretical basis for applying micropolar continuum mechanics to the analysis of earthquake focal mechanisms is described in detail by Twiss et al. [1993]. We summarize the theory below and describe modifications to the equations that we have used in this analysis.

We envision distributed brittle deformation of the Earth's crust to be similar to deformation of a granular material. The large-scale geometry of deformation is defined by the relative motion of the centers of mass of the grains, the macrodeformation, but an independent small-scale motion also occurs which is defined by the rotation of the individual grains about their centers of mass, the microspin. We distinguish these different scales of motion by the respective prefixes "macro-" and "micro-." At the scale of crustal deformation, these "grains" are rigid, fault-bounded blocks that may have dimensions of the order of hundreds to thousands of meters. Because aftershocks occur on a scale comparable to the expected dimensions of the rotating blocks, observations of these events do not average out this rotational component of the deformation, and we must take explicit account of its effects.

The motion of a deforming micropolar continuum is described by (1) a strain rate tensor $d$ (i.e., a deformation rate tensor), which is the symmetric part of the macrovelocity gradient tensor; (2) a macrospin tensor $w$, or its uniquely associated axial vector the macrovorticity, which is the antisymmetric part of the macrovelocity gradient tensor; and (3) an independent microspin tensor $\omega$. The macrospin tensor describes the average rotation rate of macromaterial lines in a classical continuum. The microspin tensor describes the independent rotation rate of rigid fault blocks, and it allows us to account for the effects of the independent block rotations on the orientations of slip vectors on the block surfaces [Twiss et al., 1991, 1993]. The microspin tensor provides additional degrees of kinematic freedom beyond what is normally considered in classical continuum theory.

The kinematic significance of the independent microspin is illustrated by the following thought experiment. Imagine a rigid block imbedded in a nondeforming continuum: If the block rotates, then the continuum shears relative to the surfaces of the block in a direction perpendicular to the rotation axis, with a shear sense determined by the sense of rotation and with a shear rate determined by the rate of rotation. If instead we hold the rigid block stationary and impose a deformation on the continuum, then that deformation also will cause material to shear past the surfaces of the rigid block in the direction of the maximum resolved rate of shear on the different surfaces and at a rate defined by the velocity gradients. In general, the shear rate vector on the block surface will be different for each of these two kinematic conditions. For a rigid block rotating in a deforming continuum, therefore, the net shear rate vector on the block surface is determined by a combination of the independent rotation rate of the block and the velocity gradients in the continuum.

We assume that seismogenic deformation accommodates a large-scale deformation that can be considered homogeneous for volumes large with respect to the scale of the seismic events. Because the direction of slip on a shear plane necessarily is the direction of maximum rate of shear on that plane, we assume that the direction of seismic slip on a plane of any given orientation is the direction of maximum resolved rate of shear of the large-scale deformation on that plane. Using the micropolar theory, we can derive a relationship that gives the theoretical slip direction $v$, a unit vector, as a function of the orientation of any shear plane defined by its unit normal $\eta$, the strain rate tensor $d$, and the relative spin tensor $\Psi$, which is the difference between the microspin and the macrospin [Twiss et al., 1991]. In the general coordinate system, which we take to be the geographic coordinates $x_{1}$ east, $x_{2}$ north, $x_{3}$ up, the relationship is

$$
v_{m}=\frac{1}{L}\left\{d_{k l}\left[\eta_{k} \delta_{l m}-\eta_{k} \eta_{l} \eta_{m}\right]+\Psi_{k m} \eta_{k}\right\}
$$

where

$$
\psi_{k m} \equiv \omega_{k m}-w_{k m},
$$

and where $\omega$ is the microspin tensor, $w$ is the macrospin tensor, $\psi$ is the relative spin tensor, $L$ is the length of the slip rate vector, $\delta$ is the Kronecker delta, and summation is understood over repeated subscripts. We can recast (1) in terms of the components of $d$ and $\Psi$ in the principal coordinates of $d$ by introducing the orthogonal transformation $Q$ from the general coordinates to the principal coordinates.

$$
d_{k l}=\hat{d}_{i j} Q_{i k} Q_{j l} \quad \psi_{k l}=\hat{\psi}_{i j} Q_{i k} Q_{j l},
$$

where the superposed circumflex indicates components in the principal coordinates of $d$. The off-diagonal components of $\hat{d}_{k l}$ are necessarily all zero.

It is easy to show that the equation for $v$ depends only on the deviatoric part of the strain rate tensor and so is independent of the volumetric part of the deformation. Thus we can replace the principal strain rates $\hat{d}_{\alpha}$ with the principal deviatoric strain rates ${ }_{\Delta} \hat{d}_{\alpha}$ defined by

$$
{ }_{\Delta} \hat{d}_{\alpha} \equiv \hat{d}_{\alpha}-\frac{1}{3}\left(\hat{d}_{1}+\hat{d}_{2}+\hat{d}_{3}\right), \quad(\alpha=1: 3)
$$

where $\hat{d}_{1} \geq \hat{d}_{2} \geq \hat{d}_{3}$; lengthening positive. From (4) we obtain 


$$
\begin{aligned}
& \Delta \hat{\mathrm{d}}_{1}=\frac{1}{3}\left[2\left(\hat{\mathrm{d}}_{1}-\hat{\mathrm{d}}_{3}\right)-\left(\hat{\mathrm{d}}_{2}-\hat{\mathrm{d}}_{3}\right)\right] \\
& \Delta \hat{\mathrm{d}}_{2}=\frac{1}{3}\left[2\left(\hat{\mathrm{d}}_{2}-\hat{\mathrm{d}}_{3}\right)-\left(\hat{\mathrm{d}}_{1}-\hat{\mathrm{d}}_{3}\right)\right] \\
& \Delta \hat{\mathrm{d}}_{3}=-\frac{1}{3}\left[\left(\hat{\mathrm{d}}_{1}-\hat{\mathrm{d}}_{3}\right)+\left(\hat{\mathrm{d}}_{2}-\hat{\mathrm{d}}_{3}\right)\right] .
\end{aligned}
$$

Substituting (3) into (1), replacing $\hat{d}_{\alpha}$ with ${ }_{\Delta} \hat{d}_{\alpha}$, and using (5) then gives, after some manipulation,

$$
v_{m}=\frac{1}{\lambda}\left\{A_{k l}\left[\eta_{k} \delta_{l m}-\eta_{k} \eta_{l} \eta_{m}\right]+B_{k m} \eta_{k}\right\}
$$

where $\lambda$ is the normalized length of the shear rate vector

$$
\lambda \equiv L /\left(\hat{d}_{1}-\hat{d}_{3}\right),
$$

where

$$
\begin{gathered}
A_{k l} \equiv D\left(Q_{2 k} Q_{2 l}-\frac{1}{3} \delta_{k l}\right)+\left(Q_{1 k} Q_{1 l}-\frac{1}{3} \delta_{k l}\right)=A_{l k} \\
B_{k l} \equiv 0.5 Q_{i k} Q_{j l} e_{m j i} \hat{W}_{m}=-B_{l k} \\
D \equiv\left(\hat{d}_{2}-\hat{d}_{3}\right) /\left(\hat{d}_{1}-\hat{d}_{3}\right) \\
\hat{W}_{k} \equiv e_{k m l} \hat{\Psi}_{l m} /\left(\hat{d}_{1}-\hat{d}_{3}\right),
\end{gathered}
$$

and where $e$ is the alternating tensor and $W$ is the normalized relative vorticity vector. For our restricted kinematic model, we require $W$ to be parallel to $\hat{d}_{2}$ by taking

$$
\hat{W}_{k}:[0, W, 0] \text {, }
$$

where $W$ therefore becomes defined by

$$
W \equiv\left(\hat{\omega}_{13}-\hat{w}_{13}\right) / 0.5\left(\hat{d}_{1}-\hat{d}_{3}\right) .
$$

The relative vorticity parameter $W$ is an objective characteristic of the deformation in the sense that it is independent of the rigid motion of the coordinate system in which it is defined [Twiss et al., 1993].

Thus the slip direction is completely determined by five independent parameters, which include the orientations of the three principal strain rate axes which are defined by three independent quantities that define the components of the orthogonal transformation $Q$; the deformation rate parameter $D$ which defines the shape of the strain rate ellipsoid; and the relative vorticity parameter $W$ which defines a normalized difference between the microspin of the rigid blocks $\omega_{13}$ and the macrospin of the deformation $w_{13}$. The inversion of seismic focal mechanism data with the micropolar theory provides best fit values for these five parameters.

The continuum measures of deformation that appear in the theory as rates (strain rates, spin) are approximated by measurements that are related to increments of deformation (incremental strains, incremental rotations), which are in effect measures of infinitesimal deformation. We obtain no explicit measure of the time increment over which the deformation increment would be averaged to give a real rate.

The micropolar inversion of seismic focal mechanism solutions does not provide a complete definition of the strain rate tensor or of the microvorticity vector. In fact, it determines only one $(D)$ of the three independent scalar invariants of the strain rate tensor, and it determines only the difference $(W)$ between the magnitudes of the macrovorticity and the microvorticity. In particular, the inversion is insensitive to the volumetric strain rate, so without in any way constraining the solution, we can assume that

$$
d_{1}+d_{2}+d_{3}=0
$$

where for convenience, we drop the superposed circumflex where it is obvious the components are referred to the principal coordinates of $d$.

For this assumption, we examine the implications of the value of $D$ for dominantly strike-slip faulting for which both $d_{1}$ and $d_{3}$ are horizontal. $D=0.5$ implies a plane strain $\left(d_{2}=0\right)$ with equal but opposite magnitudes of principal lengthening and shortening $\left(d_{1}=-d_{3}\right)$ and thus a simple shear along the strike-slip fault; $0 \leq D<0.5$ defines a prolate strain rate ellipsoid (cigar-shaped) which implies that $d_{2}$ is a shortening and thus closer in value to $d_{3}$ than it is to $d_{1}$. The deformation is equivalent to the superposition of a simple shear with a component of extension normal to the fault and shortening in the vertical direction; thus the deformation is "transtensional" and accommodates crustal thinning. $0.5<D \leq 1$ defines an oblate strain rate ellipsoid (pancake-shaped) and implies that $d_{2}$ is a lengthening and thus closer in value to $d_{1}$ than to $d_{3}$. The deformation is equivalent to the superposition of a simple shear with a shortening normal to the fault and vertical lengthening, implying that the deformation is "transpressional" and accommodates crustal thickening.

For a generalized model of shearing across a zone of deformation, the microspin is not intrinsically determined by the macrostrain rate or the macrospin but rather depends on the specific kinematics of block rotation within the deformation zone [Twiss et al., 1993]. The sign of $W$ depends on the orientation of the coordinate system, the sense of shear, and the relative magnitudes of microspin and macrospin. Looking in the positive direction along the $d_{2}$ axis, the macrovorticity has a right-handed sense about the $d_{2}$ axis for a dextral macroscopic shear. Positive values of $W$ imply that rigid fault-bounded blocks are rotating faster than, and in the same sense as, the macrovorticity; negative values of $W$ imply that the blocks are rotating more slowly than, or even in the opposite sense from, the macrovorticity. For a sinistral macroscopic shear, or equivalently if the coordinate axes are defined so that the macrovorticity has a left-handed sense about the $d_{2}$ axis, the signs of $W$ are reversed. Thus the sign of $W$ does not provide a unique interpretation of the microvorticity unless additional independent information, such as the sense of macroscopic shear relative to the positive direction of the $d_{2}$ axis, is available.

\section{Kinematic Interpretation of the Seismic $P$ and $T$ Axes}

For a given deformation geometry, micropolar theory predicts the slip direction $v$ on a plane of any orientation defined by the unit normal $\eta$ to the plane (equations (3)-(5)). The associated seismic $P$ and $T$ axes are defined by

$$
P \equiv(v-\eta) /|v-\eta| \quad T \equiv(v+\eta) /|v+\eta| .
$$

These axes define the geometry of the "local" deformation that is associated with a single slip event on a single shear plane. We assume that within a specified volume that is large compared to the characteristic dimension of a seismic event, the "global" deformation is homogeneous and is reflected by the characteristics of the group of "local" deformations associated with each seismic focal mechanism within the volume. The solution to the micropolar inverse problem used in this study relates the seismic $P$ and $T$ axes to the orientation of the principal axes of the global strain rate tensor, the shape 
of the global strain rate ellipsoid as defined by the deformation rate parameter $D$ (equation (10)), and the global relative vorticity parameter $W$ (equation (13)).

The deformation rate parameter $D$ is comparable to the reduced stress parameter $\phi$ [e.g., Angelier, 1979; Michael, 1984 ], or $R$ [Gephart, 1990] used in other inversions, where (compare equation (10))

$$
R(\text { or } \phi) \equiv\left(\sigma_{2}-\sigma_{3}\right) /\left(\sigma_{1}-\sigma_{3}\right),
$$

and $\sigma_{\mathrm{k}}$ are the principal stresses $\left(\sigma_{1} \geq \sigma_{2} \geq \sigma_{3}\right.$; compression positive). $\quad R$ or $\phi$ simply define the shape of the stress ellipsoid. If we assume a direct equivalence between $d_{1}$ (maximum lengthening rate) and $\sigma_{3}$ (minimum compressive stress) and between $d_{3}$ (maximum shortening rate) and $\sigma_{1}$ (maximum compressive stress), then

$$
R(\text { or } \phi)=1-D \text {. }
$$

If we constrain our inversion by setting $W=0$, then our results for the orientation of principal strain rate axes and for $D$ should be comparable to those obtained by previous inversions for the principal stress axes and for $R$ (or $\phi$ ). Thus in a formal sense, previous inversion schemes are a special case of our scheme, but our inversion uses a different measure of misfit (see Appendix A), our inversion is unique in accounting for the effects of possible block rotations, and we maintain that the results of the inversion are better interpreted as characterizing the deformation rather than the stress.

In adopting this deformation interpretation, we argue that the measurements by which the $P$ and $T$ axes are defined are directly related to the displacement on the fault and that therefore (1) the seismic $P$ and $T$ axes (equation (15)) define the local principal strain rate axes, not the local principal stress axes; (2) the slip directions on the shear planes are the directions of the maximum resolved rate of shear of the global deformation rather than the direction of the maximum resolved shear stress; and (3) the inversion provides the orientations and relative magnitudes of the principal global strain rates, not the principal global stresses. This difference in approach has allowed us to derive the effects of rigid block rotation on the slip directions [Twiss et al., 1991] and on the antisymmetric part of a generalized micropolar seismic moment tensor [Twiss et al., 1993].

Assuming the stress interpretation, alternatively, is assuming in effect that the material behaves as an isotropic, constitutively linear material, because the principal axes of stress can only parallel those of the strain rate (or infinitesimal strain) if the material is isotropic, and the relative magnitudes of the principal stresses and those of the principal strain rates (or infinitesimal strains) can only be related by (17) if the constitutive equations describing the material behavior are linear. Because these assumptions are not obviously appropriate, we prefer the deformation interpretation to the stress interpretation.

\section{Methods of Data Analysis}

Earthquake data used in this study were recorded by the California Institute of Technology and the U.S. Geological Survey. Data consist of focal mechanisms for the 1992 Joshua Tree and Landers earthquake sequences, as well as background seismicity in the Mojave block between 1981 and 1991. The methodology for determining focal mechanisms is described by Hauksson [1994].
The focal mechanisms were subdivided into groups corresponding to individual geometric surface fault segments. For aftershocks that occurred on blind structures with no surface expression, such as the Joshua Tree sequence and the Big Bear aftershocks, fault segments were identified based on alignments of epicenters that define a distinct trend or orientation. Seismic $P$ and $T$ axes were determined for focal mechanisms using the algorithm PTFROMDAT, and displayed on equal-area, lower hemisphere, Kamb-contour plots using Allmendinger's plotting program Stereonet 4.7-IIa. For most subsets of the data, the contour plots reveal well-defined $P$ and $T$ maxima, which we interpret as evidence that the data reflect a homogeneous deformation within the volume containing those aftershocks. Visual inspection of the initial Kamb contour plots also revealed examples where the $P$ and $T$ axes did not form well-defined maxima. In each of these cases, we reassessed the criteria for defining the fault segment, and we redefined the segment boundaries as appropriate until the $P$ and $T$ axes formed well-defined maxima on a single Kamb-contour plot.

We determined the orientations of the principal strain rate axes and values of the deformation rate parameter $D$ and the relative vorticity parameter $W$ for each group of $P$ and $T$ axes using the grid-search algorithm described in Appendix A. The solutions presented in Table 1 give the orientations of $d_{1}$ and $d_{3}$ to within the grid spacing of $\pm 2.5^{\circ}$ and the values of $D$ and $W$ to within the grid spacing of \pm 0.05 .

We determined the orientation and magnitude of the horizontal principal strains associated with the Landers earthquake by inverting geodetic displacements determined by Global Positioning System (GPS) and other geodetic techniques. We then compared the geodetically determined coseismic crustal strains in the Mojave block to the seismogenic strains determined from inversion of the aftershock data. The geodetic data consist of the magnitude and direction of station displacements reported by Hudnut et al. [1994] for geodetic measurements that span the period from a time before the Landers earthquake but after the Joshua Tree earthquake to a time shortly after the Landers earthquake. We divided the central Mojave block into cells, mostly of triangular shape, whose vertices are at the geodetic measurement stations (Figure 2), and we inverted the geodetically measured displacements for the displacement gradient tensor in the horizontal plane using GPSTRN, our revision of an algorithm provided by A. Donnellan of the Jet Propulsion Laboratory (Pasadena, California). From this tensor we determined the orientation and magnitude of the principal horizontal strains and the vertical axis rotations in each triangular cell.

The solution for the gradients of the displacement component that parallel each coordinate direction is a weighted least squares solution to the linear inverse problem [Menke 1984, equation 3.37], where the weighting matrix is a diagonal matrix composed of the inverse variances of each measurement. For a triangular cell, however, this inverse problem provides an exact solution because there are as many independently determined displacement gradients as there are unknowns in the two-dimensional displacement gradient tensor. We are particularly interested in the cells that span the surface rupture of the Landers earthquake and those that lie above the blind fault associated with the Big Bear aftershock (Figure 3), because the strains in these cells should most closely reflect the coseismic deformation associated with these particular events. 
Table 1. Results of Micropolar Inversion

\begin{tabular}{|c|c|c|c|c|c|c|c|c|}
\hline Domain & $\frac{d_{1}}{\text { (Trend, Plunge) }}$ & $\begin{array}{c}d_{1} \\
\text { (Azimuth) }\end{array}$ & $\begin{array}{c}d_{3} \\
\text { (Trend, } \\
\text { Plunge) }\end{array}$ & $D$ & $W$ & Mn cos & $\begin{array}{c}\cos ^{-1} \\
(\mathrm{Mn} \cos )\end{array}$ & $\begin{array}{l}\text { Number } \\
\text { of Data }\end{array}$ \\
\hline $\begin{array}{l}\text { South Joshua } \\
\text { Joshua ENE } \\
\text { North Joshua }\end{array}$ & $\begin{array}{c}108.59,6.97 \\
113.69,10.74 \\
118.87,11.77\end{array}$ & $\begin{array}{l}\text { N7IW } \\
\text { N66W } \\
\text { N61W }\end{array}$ & $\begin{array}{c}20.13,-12.44 \\
24.48,-4.16 \\
34.81,-24.22\end{array}$ & $\begin{array}{l}0.4 \\
0.5 \\
0.4\end{array}$ & $\begin{array}{l}0.1 \\
0.3 \\
0.3\end{array}$ & $\begin{array}{l}0.986 \\
0.985 \\
0.989\end{array}$ & $\begin{array}{l}9.418 \\
9.997 \\
8.495\end{array}$ & $\begin{array}{l}142 \\
326 \\
141\end{array}$ \\
\hline $\begin{array}{l}\text { Yucca Valley } \\
\text { South Johnson } \\
\text { Valley Fault }\end{array}$ & $\begin{array}{l}109.98,0.44 \\
113.02,-0.44\end{array}$ & $\begin{array}{l}\text { N70W } \\
\text { N67W }\end{array}$ & $\begin{array}{c}20,-9.98 \\
23.02,0.02\end{array}$ & $\begin{array}{l}0.5 \\
0.5\end{array}$ & $\begin{array}{c}0 \\
-0.2\end{array}$ & $\begin{array}{l}0.987 \\
0.987\end{array}$ & $\begin{array}{l}9.396 \\
9.337\end{array}$ & $\begin{array}{l}180 \\
113\end{array}$ \\
\hline $\begin{array}{l}\text { North Johnson } \\
\text { Valley Fault }\end{array}$ & $107.96,22.68$ & $\mathrm{~N} 72 \mathrm{~W}$ & $20.82,-6.81$ & 0.6 & 0.2 & 0.981 & 11.323 & 78 \\
\hline $\begin{array}{l}\text { Kickapoo Fault } \\
\text { Homestead Valley } \\
\text { Fault }\end{array}$ & $\begin{array}{l}124.59,-0.50 \\
136.04,-6.23\end{array}$ & $\begin{array}{l}\text { N55W } \\
\text { N44W }\end{array}$ & $\begin{array}{c}34.50,-10.0 \\
44.39,-13.95\end{array}$ & $\begin{array}{l}0.5 \\
0.5\end{array}$ & $\begin{array}{l}0.4 \\
-0.1\end{array}$ & $\begin{array}{l}0.977 \\
0.974\end{array}$ & $\begin{array}{l}12.281 \\
13.037\end{array}$ & $\begin{array}{l}104 \\
110\end{array}$ \\
\hline $\begin{array}{l}\text { NW Camp Rock } \\
\text { Fault }\end{array}$ & $53.5,-4.55$ & $\mathrm{~N} 36 \mathrm{~W}$ & $323.9,5.4$ & 0.5 & -0.1 & 0.965 & 15.103 & 114 \\
\hline $\begin{array}{l}\text { Calico-Camp Rock } \\
\text { Barstow Area } \\
\text { Mojave Valley } \\
\text { Pisgah Fault }\end{array}$ & $\begin{array}{c}128.83,-1.38 \\
103.08,9.50 \\
115,5 \\
123.58,-23.64\end{array}$ & $\begin{array}{l}\text { N5IW } \\
\text { N77W } \\
\text { N65W } \\
\text { N56W }\end{array}$ & $\begin{array}{c}38.61,-14.35 \\
13.17,-0.49 \\
25,0 \\
23.74,-21.33\end{array}$ & $\begin{array}{l}0.4 \\
0.6 \\
0.5 \\
0.5\end{array}$ & $\begin{array}{l}-0.1 \\
0.3 \\
-0.3 \\
-0.3\end{array}$ & $\begin{array}{l}0.969 \\
0.989 \\
0.997 \\
0.992\end{array}$ & $\begin{array}{l}14.278 \\
8.473 \\
4.698 \\
6.011\end{array}$ & $\begin{array}{c}73 \\
101 \\
18 \\
37\end{array}$ \\
\hline $\begin{array}{l}\text { Big Bear } \\
\text { Frontal Fault } \\
\text { SE San Bernardino } \\
\quad \text { Mountains }\end{array}$ & $\begin{array}{l}89.49,-5.83 \\
89.83,0.98 \\
94.61,9.96\end{array}$ & $\begin{array}{l}\text { N91W } \\
\text { N90W } \\
\text { N85W }\end{array}$ & $\begin{array}{c}357.98,-14.47 \\
0,-10 \\
5.42,-4.58\end{array}$ & $\begin{array}{l}0.5 \\
0.4 \\
0.7\end{array}$ & $\begin{array}{c}0.1 \\
-0.1 \\
-0.4\end{array}$ & $\begin{array}{l}0.986 \\
0.991 \\
0.984\end{array}$ & $\begin{array}{l}9.665 \\
7.327 \\
7.373\end{array}$ & $\begin{array}{l}325 \\
112 \\
39\end{array}$ \\
\hline $\begin{array}{l}\text { SW San Bernardino } \\
\text { Mountains }\end{array}$ & $81.00,0.00$ & N99W & $351.00,0.00$ & 0.5 & 0.3 & 0.994 & 4.789 & 75 \\
\hline San Andreas Fault & $89.0,-5.70$ & N91W & $357.18,-20.16$ & 0.7 & 0 & 0.986 & 9.662 & 80 \\
\hline $\begin{array}{l}\text { Background } \\
\text { Eastern California } \\
\text { Shear Zone }\end{array}$ & $109.01,4.47$ & N7IW & $19.51,-6.31$ & 0.4 & 0.4 & 0.991 & 7.855 & 84 \\
\hline $\begin{array}{l}\text { San Bernardino } \\
\text { Mountains }\end{array}$ & $80,-10$ & Nloow & $352.66,14.77$ & 0.5 & 0.1 & 0.990 & 7.961 & 67 \\
\hline $\begin{array}{c}\text { Homestead Valley } \\
\text { Earthquake }\end{array}$ & $117.81,-4.89$ & N62W & $28.02,1.43$ & 0.5 & -0.1 & 0.984 & 10.378 & 211 \\
\hline $\begin{array}{c}\text { Galway Lake } \\
\text { Earthquake }\end{array}$ & $120.36,0.89$ & N60W & $30.52,-9.94$ & 0.3 & -0.2 & 0.996 & 5.154 & 18 \\
\hline
\end{tabular}

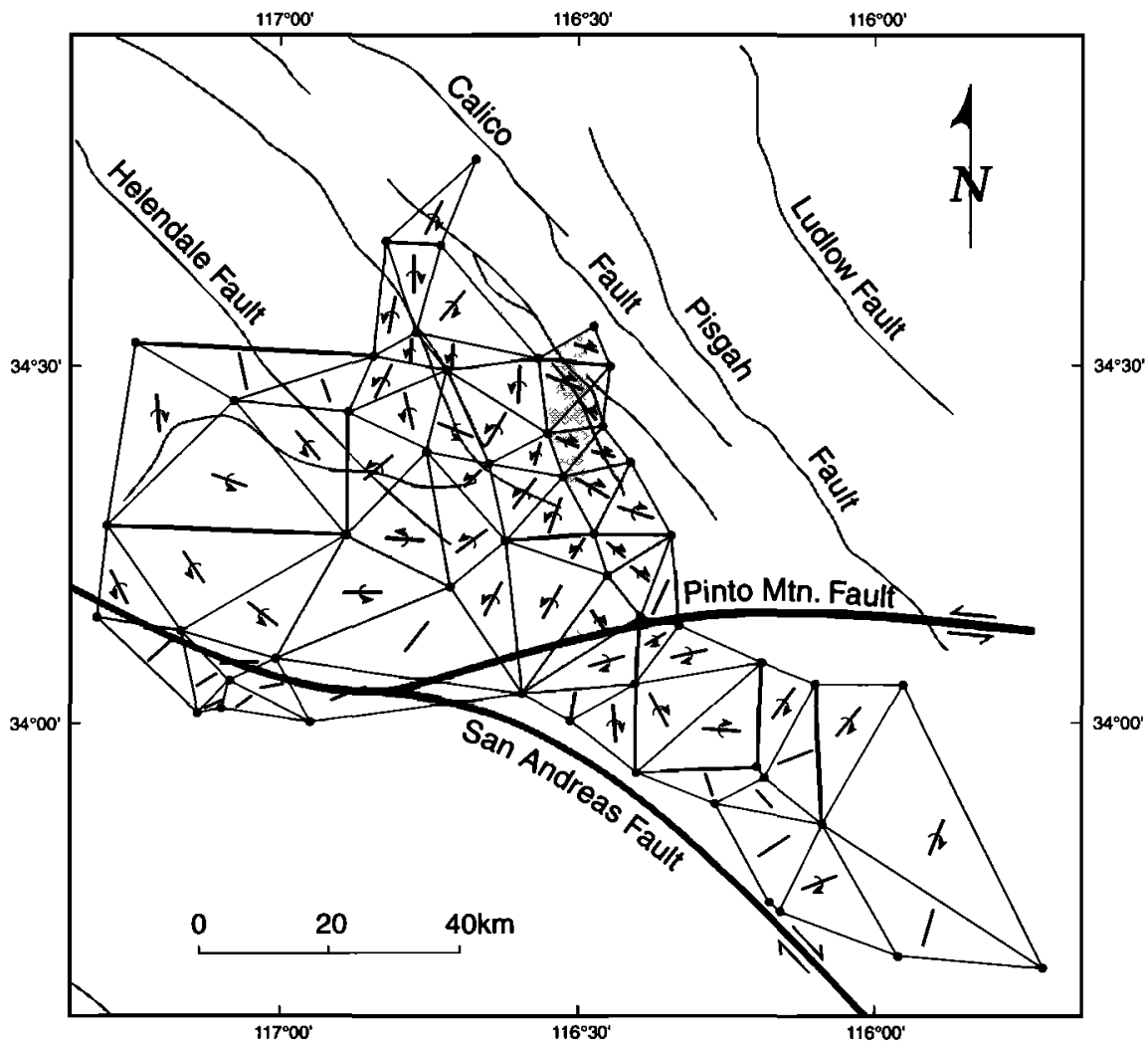

Figure 2. Coseismic strain and rotation field in the central Mojave block from inversion of GPS data. Vertices of triangular elements are defined by locations of geodetic measurement stations. Lines within each element show the direction of maximum principal extension $\left(d_{1}\right)$. Arrows show sense of rotation (clockwise or counterclockwise) associated with the coseismic deformation. Elements that span the Landers surface rupture and the northeast trending Big Bear shear zone are highlighted with gray shading and are shown in more detail in Figure 4. 


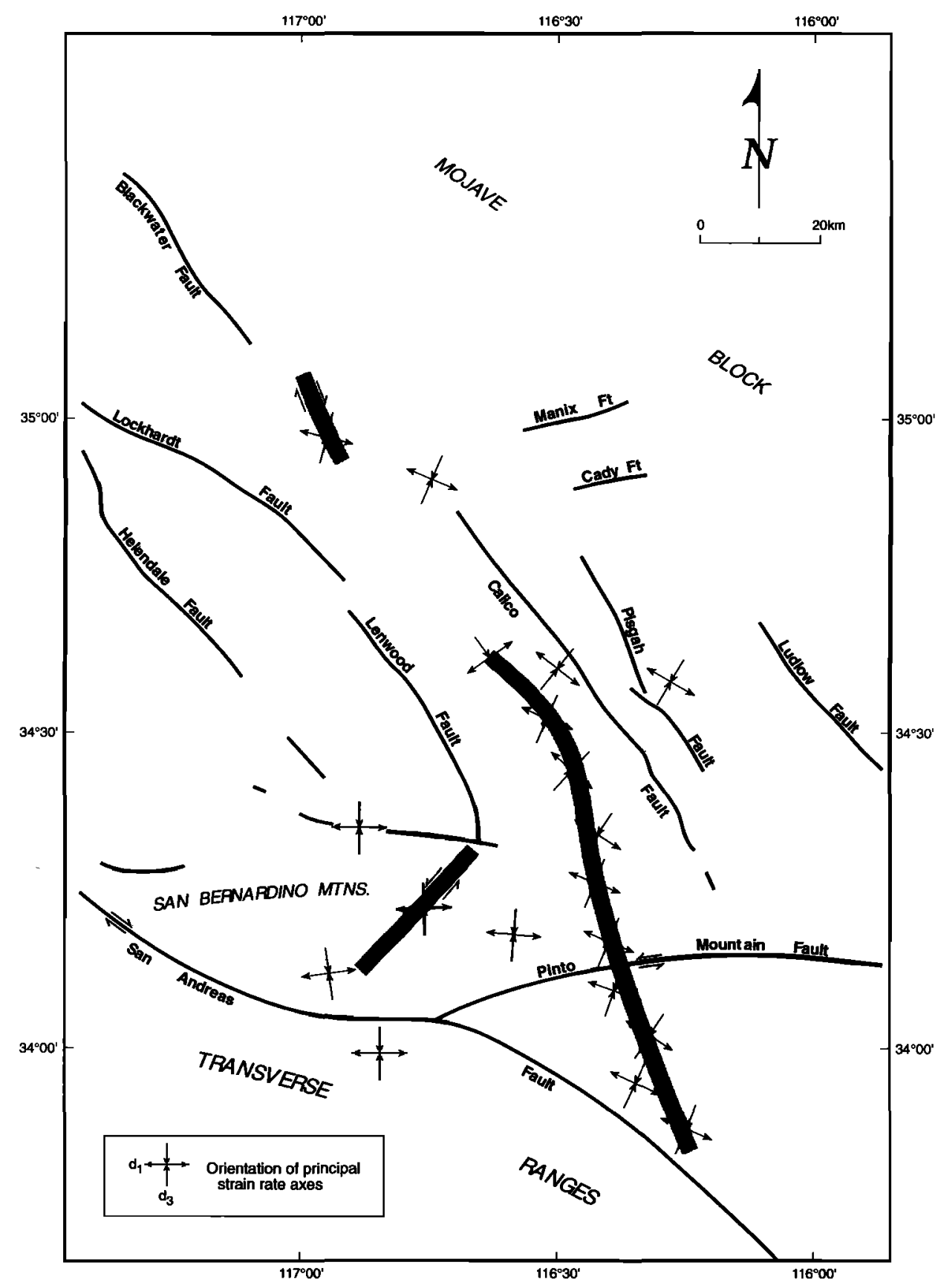

Figure 3. Orientations of principal strain rate axes $\left(d_{1}\right.$ maximum extension rate; $d_{3}$ maximum contraction rate) inferred from a micropolar inversion of seismic focal mechanism solutions.

\section{Results From Inversions of Focal Mechanism and Geodetic Data}

In this section we present the results of the micropolar inversion of aftershock $P$ and $T$ axes (Table 1 and Figure 3) for (1) the Joshua Tree sequence; (2) aftershocks along the trace of the Landers surface rupture and in the central Mojave block; (3) the Big Bear earthquake and aftershocks in the San Bernardino Mountains; and (4) pre-1992 background seismicity in the central Mojave block. We compare the orientations of the seismogenic $d_{1}$ (extension rate) axes with the orientations of the maximum principal extension axes determined from inversion of the geodetic data (Figure 4).

\section{Joshua Tree Earthquake Sequence}

The $M_{w} 6.1$ Joshua Tree earthquake preceded the Landers earthquake by 2 months and is interpreted to be a preshock of the larger sequence [Hauksson et al., 1993]. The Joshua Tree mainshock occurred in the Little San Bernardino Mountains south of the Landers mainshock. The majority of the aftershocks define a northerly trend that extends for approximately $25 \mathrm{~km}$ between the Pinto Mountain and San Andreas faults (Figures 3 and 5). A less well-defined eastnortheast alignment of aftershocks occurred near the southern end of the aftershock zone. The majority of focal mechanisms indicate dextral strike-slip faulting on north to northwest 


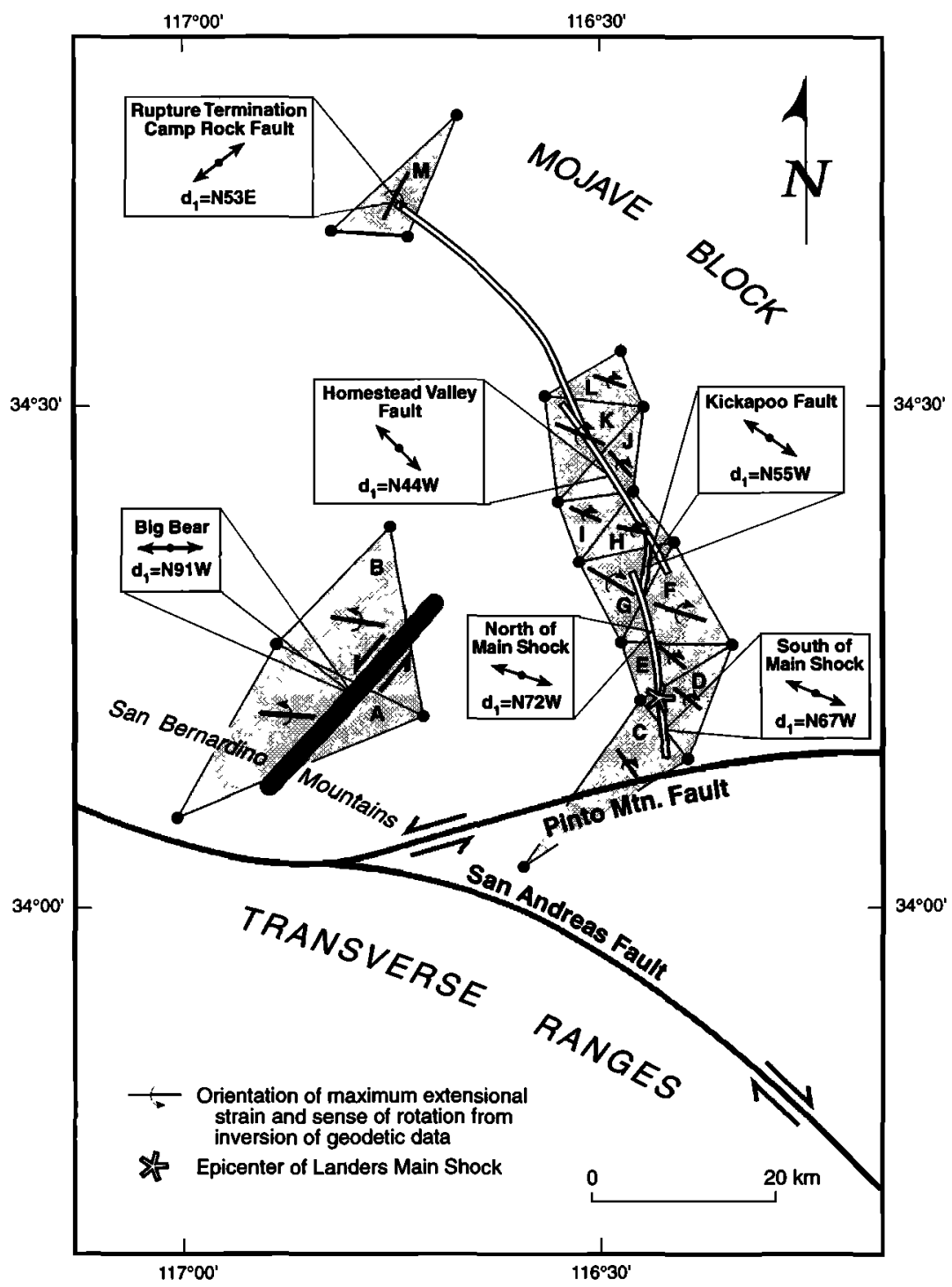

Figure 4. Detailed map comparing the direction of maximum extension obtained from inversion of geodetically determined surface displacements, and the orientation of $\mathrm{d}_{1}$ obtained from micropolar inversion of seismic $P$ and $T$ axes.

striking nodal planes or sinistral strike-slip faulting on ENE striking nodal planes. No surface rupture was observed following the earthquake [Hauksson et al., 1993].

Based on a visual inspection of the aftershock distribution, we divided the events into three groups (Figure 5): (1) the southern part of the northerly alignment, which trends slightly west of north; (2) the northern part of the northerly alignment, which trends slightly east of north; and (3) the east-northeast alignment. In general, micropolar inversion of $P$ and $T$ axes for all three groups indicates that $d_{1}$ for the Joshua Tree sequence is NW-SE, and that $d_{3}$ is NE-SW (Table 1 and Figure 3). Values of the deformation rate parameter $D$ range between 0.4 and 0.5 and with $d_{2}$ essentially vertical. This range indicates that the deformation primarily is characterized by shearing, possibly accompanied by a minor component of transtension and crustal thinning.

In order to interpret the kinematic significance of the nonzero values of $W$ associated with the Joshua Tree aftershocks (Table 1), it is neccessary to determine the sense of rotation (the macrospin) across the seismogenic shear zones. The sense of the macrospin is well-constrained for the Landers surface rupture north of the Joshua Tree sequence by inversion of geodetic data (Figure 4; see discussion below). Similar data to constrain the macrospin for the Joshua Tree earthquake are not available, however. In the absence of external (i.e., geodetic) constraints, we assume that the sense of the macrospin is consistent with the direction of macroscopic shearing. For the southern and northern segments of the north trending aftershock alignment, we assume that the sense of shear is right-lateral based on focal mechanisms showing right-lateral slip on north striking nodal planes [Hauksson et al., 1993], and that the corresponding macrospin is clockwise looking down. Using the right-hand rule, a clockwise macrospin is represented by a positivedownward axial vector. Because we assume that the axial relative vorticity vector is parallel to the $d_{2}$ axis, this requires choosing a coordinate system where the $d_{2}$ axis also is positive downward (Table 1). We adopt this orientation as the standard for our analysis, with the realization that if the sense of shear is left lateral, then the sign of $W$ will be the opposite 
1992 JOSHUA TREE SEQUENCE

22 April - 30 June

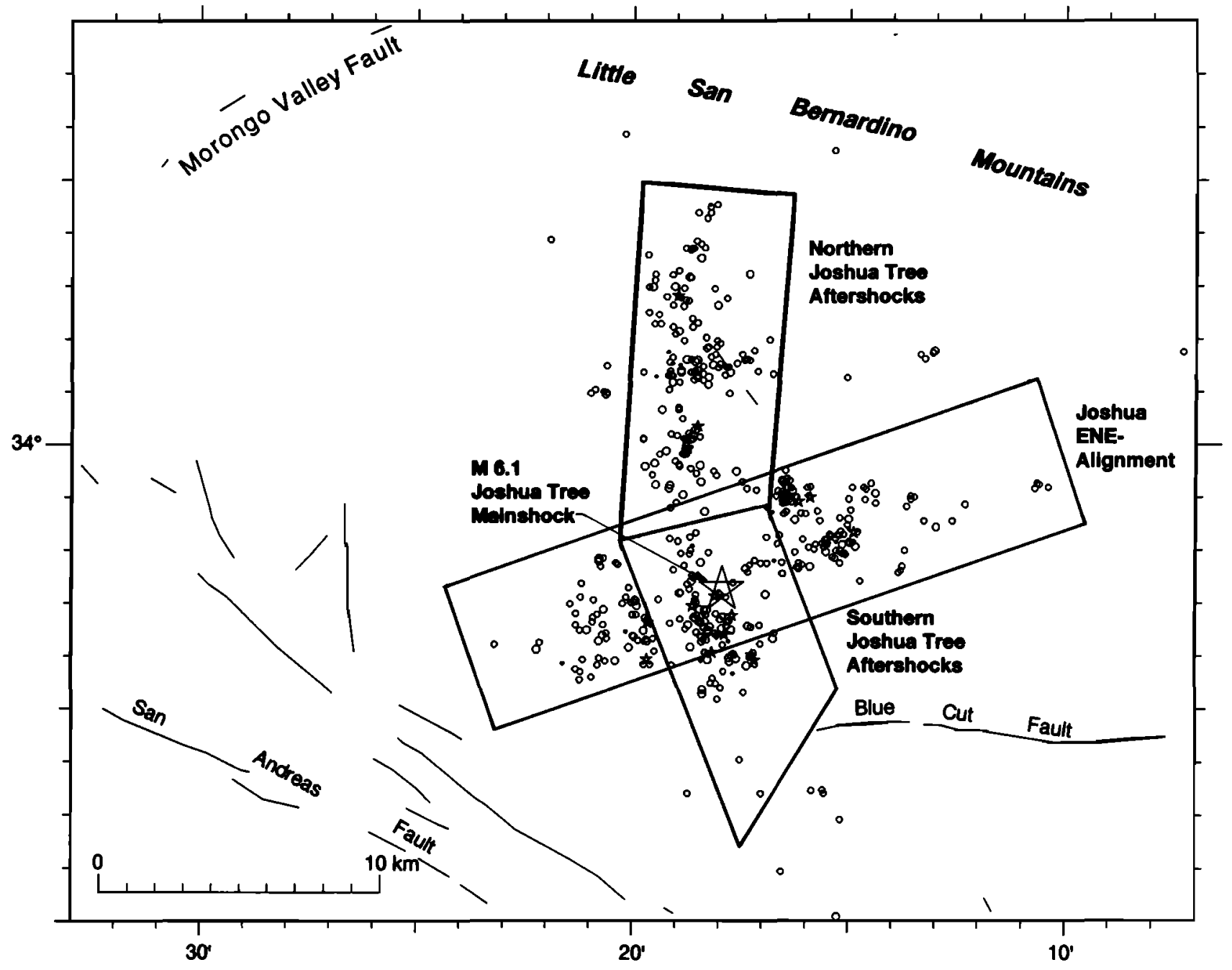

Figure 5. Epicenters of the Joshua Tree sequence aftershocks.

of that for a right lateral shear, all other things being equal (see the discussion of the sign of $W$ in the second section). Although the sign of $W$ is the same for all domains of the Joshua Tree alignment, that constraint does not uniquely define the shear sense of the deformation. We presume, in fact, that the sense of shear for the ENE alignment of aftershocks is sinistral because focal mechanisms indicate left-lateral strikeslip motion on ENE striking nodal planes [Hauksson et al., 1993].

With these assumptions, the positive values of $W$ for the two segments of the north trending aftershock alignment (Table 1) imply that the rotation rate of fault-bounded blocks within the shear zone (the microspin) is greater than the macrospin. If the deformation associated with the ENE alignment includes a dextral shear, then the macrospin would be clockwise and the positive value of $W$ in this domain would be consistent with the values in the other domains. If, however, the shear is sinistral, as would be anticipated for this conjugate alignment, then the macrospin would be counterclockwise, and the value of $W$ would imply a block rotation rate that is less than the rotation rate defined by the macrospin.

\section{The Landers Earthquake Sequence}

We divided aftershocks along the primary surface rupture into groups that correspond to geometric fault segments or alignments of seismicity with a distinct strike and that are separated from adjacent segments by abrupt changes in strike or changes in the style of faulting (Figure 6). Most of the seismogenic segments are associated with surface faults mapped by previous workers (see synthesis of Dokka and Travis [1990]). Several notable exceptions include the north trending Yucca Valley alignment, the east-northeast trending Calico-Camp Rock alignment (Figure 6), the north-northwest trending Barstow alignment, and Mojave Valley aftershocks (Figure 7), none of which are associated with previously mapped faults. In addition, we divided the Johnson Valley fault into two segments separated by the Landers mainshock (Figure 6), based on significantly different patterns of $P$ and $T$ axes for each segment revealed in Kamb contour plots.

In general, inversion of the $P$ and $T$ axes shows that $d_{1}$ is oriented NW-SE and $d_{3}$ is oriented NE-SW along the trend of the surface rupture (Table 1 and Figure 3 ). The orientations of $d_{1}$ and $d_{3}$ in the northern part of the Landers surface rupture are 


\section{LANDERS EARTHQUAKE SEQUENCE June - December 1992}

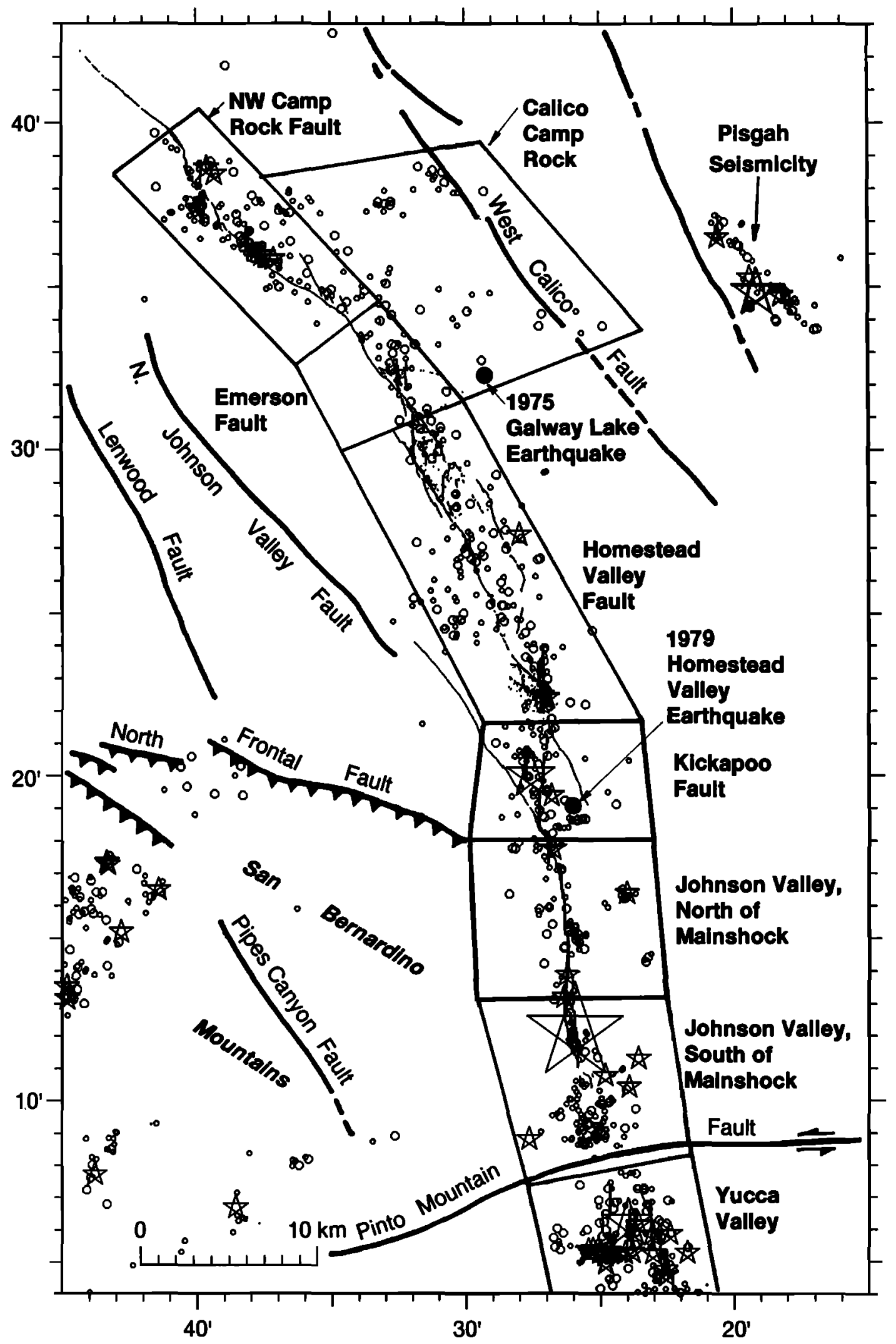

Figure 6. Aftershocks associated with the Landers surface rupture and off-fault clusters of seismicity in the central Mojave desert. 


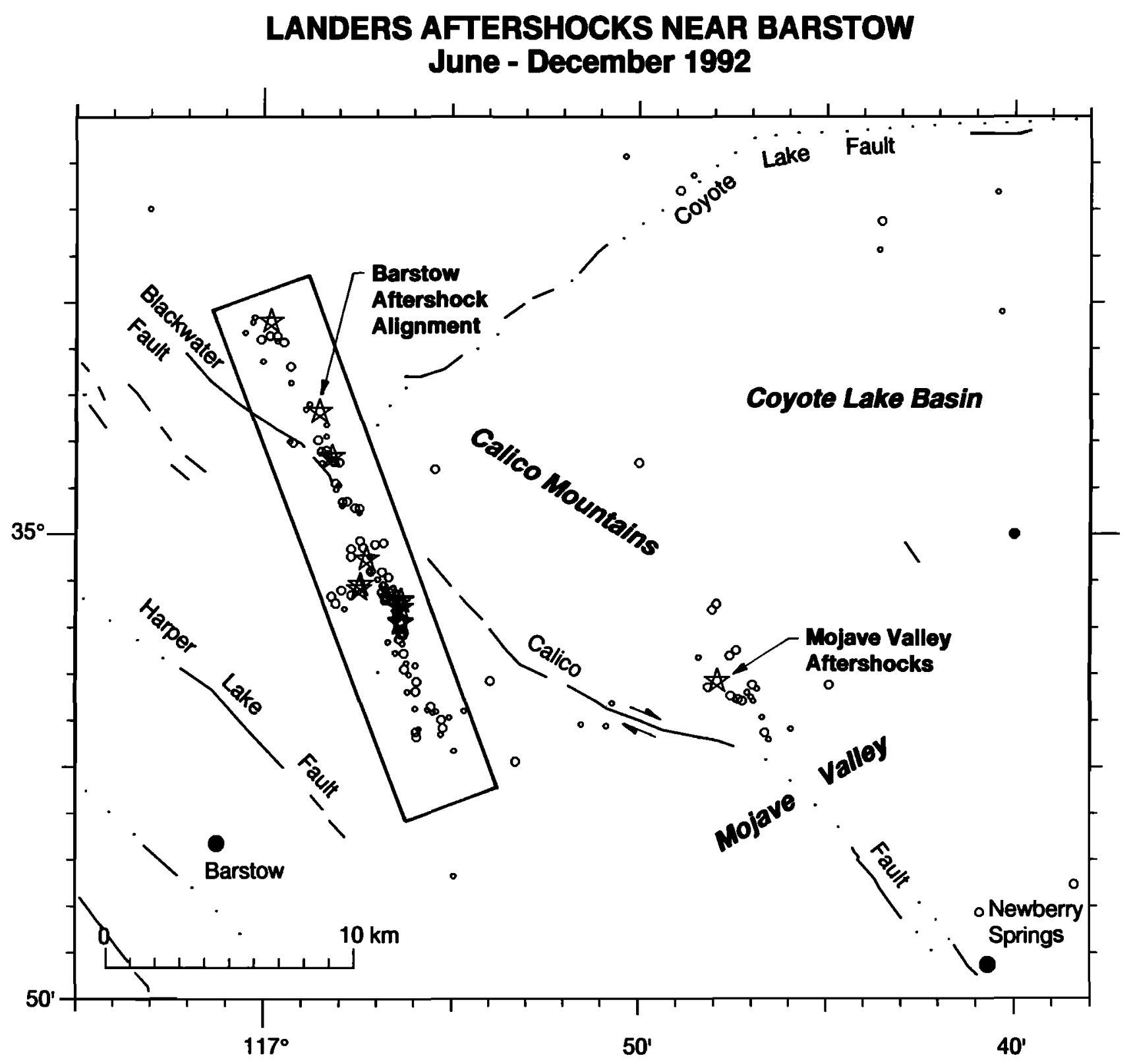

Figure 7. Seismicity in the Barstow and Mojave Valley areas.

in general rotated somewhat clockwise relative to those in the southern part, except for near the termination of the rupture at ihe nurihwesi end of the Canp Rouck fauli where the axes appear to exchange orientations (Table 1 and Figure 3). This change in orientation is associated with an anomalous pattern of aftershocks relative to the rest of the surface rupture, as previously recognized by Hauksson [1994]. The orientations of $d_{1}$ and $d_{3}$ in this region, however, are consistent with dextral shear at the northwestern end of the Camp Rock fault. The strike of the fault in this region is approximately $\mathrm{N} 58^{\circ} \mathrm{W}$, which is approximately $12^{\circ}$ westerly of the orientation of $d_{3}$ (Table 1). This implies that the components of $d_{1}$ and $d_{3}$ resolved across the fault are consistent with dextral shear, even though the fault is not parallel to the plane of the maximum resolved rate of shear (i.e., at $45^{\circ}$ from $d_{1}$ and $d_{3}$ ).

Inversion of the geodetic displacements along the trend of the surface rupture (Figure 4) also gives generally NW-SE orientations for the axis of maximum extension, consistent with the results from the inversion of the seismic focal mechianisms. Even the very diff́erent $\mathrm{NE} E-\mathrm{S} W$ orientation of the maximum extension axis that we inferred from the seismic focal mechanisms at the NW end of the Camp Rock fault is reproduced by the geodetic data.

Individual orientations of the geodetic strain axes differ locally from the focal mechanism strain rate axes by $0-35$ degrees (Figure 4 and Table 2). The geodetic stations, however, are not distributed symmetrically across the fault zone, and in places they are at distances of up to several kilometers from the fault zone. Thus the strain calculated for each cell is averaged out over a significant area around the fault zone. Moreover, the fault segments used for the inversion of the focal mechanism data do not coincide with the segments that lie within each of the cells defined by the geodetic stations. It is not surprising, therefore, that the results from 
Table 2. Comparison of Geodetic and Micropolar Inversion Results

\begin{tabular}{rlrc}
\hline Cell & $\begin{array}{c}\text { Geodetic Stations Forming } \\
\text { Cell Boundaries }\end{array}$ & $\begin{array}{c}\text { Direction of Maximum } \\
\text { Extension }\end{array}$ & $\begin{array}{c}\text { Orientation of } \\
d_{1}, \begin{array}{c}\text { Micropolar Inversion } \\
\text { (Table })\end{array}\end{array}$ \\
\hline A & ONYX; MILL; BEAR & $89.64 \pm 1.70$ & $89^{\circ}\left(\Delta=0.64^{\circ}-17^{\circ}\right)$ \\
C & ONYX; OLDW; BEAR & $106.16 \pm 9.03$ & $113^{\circ}\left(\Delta=25^{\circ}-35^{\circ}\right)$ \\
D & PAXN; 6054; 6058 & $148.99 \pm 0.43$ & \\
E & 6050; 6054; PAXN & $138.34 \pm 1.28$ & $108^{\circ}\left(\Delta=2^{\circ}-20^{\circ}\right)$ \\
F & 6050; RICH; 6054 & $128.17 \pm 1.54$ & \\
G & 7050; 7002; RICH & $110.09 \pm 1.05$ & $125^{\circ}\left(\Delta=9^{\circ}-22^{\circ}\right)$ \\
H & 7002; MAUM; LAZY & $117.91 \pm 0.56$ & $136^{\circ}\left(\Delta=0.35^{\circ}-25^{\circ}\right)$ \\
I & MAUM; MEAN; LAZY & $103.41 \pm 0.06$ & \\
J & LEDG; MEAN; MAUM & $115.99 \pm 0.05$ & $53^{\circ}\left(\Delta=25^{\circ}\right)$ \\
K & LEDG; BOUL; MEAN & $136.35 \pm 0.08$ & $122.98 \pm 0.11$ \\
L & LEDG; 7001; BOUL & $108.28 \pm 0.14$ & \\
M & DUMP; ORD; 7000 & $28.34 \pm 8.48$ & \\
& & &
\end{tabular}

the two sources of data differ somewhat. Nevertheless, the orientations of the principal axes given by the two independent data sets are in substantial agreement, and we conclude that the strain recorded by the aftershocks is substantially of the same geometry as that released during the main seismic event.

The majority of $D$ values along the trend of the surface rupture are 0.5 or at most within 0.1 of 0.5 (Table 1), implying that deformation is characterized primarily by plane strain. The $d_{1}$ and $d_{3}$ axes are essentially horizontal, $d_{2}$ axes are essentially vertical, and the seismogenic zones define vertical planes. Thus the values of $D$ imply a deformation within the seismogenic shear zones that is predominantly strike-slip shearing with no consistent crustal thickening or thinning.

Values of $W$ obtained from the inversion range from -0.3 to 0.4 along strike of the main surface rupture (Table 1), suggesting considerable variation in the kinematics of rotating blocks within the seismogenic shear zones. We refer these values of $W$ to the principal coordinates for the strain rate tensor chosen such that $d_{2}$ and the axial microvorticity vector are positive downward (Table 1). In this orientation, the macrospin for dextral shear on the faults is clockwise, and this is consistent with the rotation inferred from the inversion of the geodetic coseismic displacements along the surface rupture (Figure 4).

Some of the variations in $W$ appear to be correlated with changes in the pattern of surface faulting along strike. South of the Landers mainshock, surface rupture along the Johnson Valley fault generally is confined to a single, narrow zone of right-lateral strike-slip faulting [Johnson et al., 1993; Sowers et al., 1994]. The associated value of $W$ for this segment is -0.2 (Table 1), indicating that blocks within the fault zone are rotating at less than the full macrospin rate. North of the mainshock, the Johnson Valley fault broadens into a zone of distributed surface fracturing. The zone progressively widens northward until it reaches a maximum E-W width of approximately $2.5 \mathrm{~km}$ in Homestead Valley along the Kickapoo fault between the Johnson Valley and Homestead Valley faults (Figure 6). The corresponding values of $W$ for the northern segment of the Johnson Valley fault and Kickapoo fault are 0.2 and 0.4 , respectively, indicating clockwise block rotation rates in excess of the macrospin rates. In the next section we discuss in greater detail the implication that seismic data record the effects of block rotations, and we also present independent structural data from the Kickapoo fault area that support this interpretation.

In three areas north and east of the Landers surface rupture (Camp Rock-Calico, Figure 6; Barstow, and Mojave Valley, Figure 7), $d_{1}$ is oriented NW-SE and $d_{3}$ is oriented NE-SW (Table 1 and Figure 3). In general, seismicity in these areas was not accompanied by primary surface faulting. Discontinuous surface fractures were observed locally and interpreted as triggered slip on the faults [Hart et al., 1993]. Detailed mapping of minor extensional surface fractures in the vicinity of Newberry Springs in southern Mojave Valley (Figures 1 and 7) indicates that the direction of maximum extension there, taken to be perpendicular to the strike of normal faults, is approximately $\mathrm{N} 60^{\circ}-65^{\circ} \mathrm{W}$ [Unruh et al., 1994]. The orientation of $d_{1}$ obtained from the micropolar inversion of $P$ and $T$ axes in Mojave Valley (N65 ${ }^{\circ} \mathrm{W}$, Table 1) is in good agreement. Inversion of $P$ and $T$ axes from a cluster of aftershocks in the vicinity of the Pisgah fault (Figure 6) indicates $d_{1}$ oriented approximately NW-SE and $d_{3}$ oriented approximately NE-SW (Table 1 and Figure 3), in agreement with the general NW-SE orientation of $d_{1}$ observed along the main surface rupture trace and elsewhere in the central Mojave block.

\section{San Bernardino Mountains and the San Andreas Fault}

We divided aftershocks in the southwestern Mojave block into several domains (Figure 8): (1) the region encompassing the Big Bear earthquake and related seismicity in the central San Bernardino mountains; (2) the region encompassing aftershocks in the vicinity of the Frontal thrust fault, northern San Bernardino mountains; (3) a cluster of seismicity in the southwestern San Bernardino Mountains; (4) distributed 


\section{LANDERS AFTERSHOCKS NEAR BIG BEAR June - December 1992}

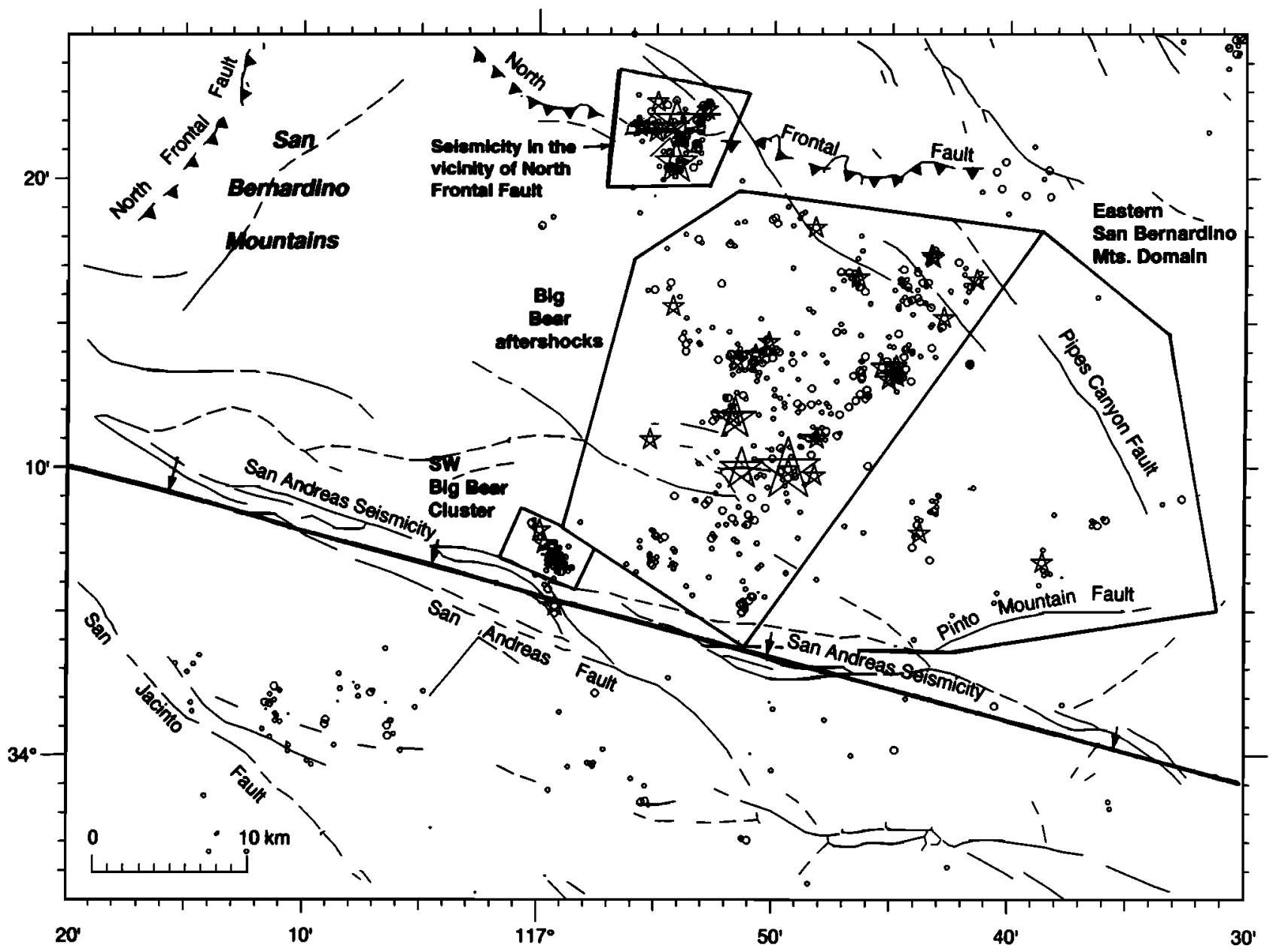

Figure 8. Aftershocks associated with the Landers and Big Bear earthquakes in the San Bernardino Mountains and related seismicity associated with the San Andreas fault along the southwestern margin of the Mojave block.

seismicity east of the Big Bear rupture; and (5) the region encompassing the San Andreas fault along the southern margin of the San Bernardino Mountains.

In all domains of the San Bernardino Mountains, $d_{1}$ is oriented nearly east-west and $d_{3}$ is oriented nearly north-south (Table 1 and Figure 3). This orientation is distinctly different from the orientation along the main Landers rupture to the east. The orientations of maximum extensional strain derived frum inversion of geodetic displacements in the triangular cells that span the Big Bear seismogenic zone (Figure 4) also are approximately east-west and thus are consistent with the orientations of the $d_{1}$ principal strain rate axes for the Big Bear earthquake obtained from the micropolar inversion.

Inversion of the geodetic data indicate that the sense of macrorotation associated with the Big Bear earthquake is counterclockwise (Figure 4). Using a coordinate system where $d_{2}$ and the microspin axial vector are positive downward, the small values of $W=0.1$ for the Big Bear aftershocks and $W=$ -0.1 for the aftershocks near the Frontal fault (Table 1) suggest that the block rotation rate within these seismogenic shear zones may be slightly different from the macrospin, but we are not confident that this value of $W$ is significantly different from zero (see Appendix B). The value of $W=0.3$ for the cluster of events southwest of the Big Bear aftershocks suggests a block rotation rate in excess of the macrospin, and the value of $W=-0.4$ for events east of Big Bear suggests a block rotation rate less than the macrospin. Without independent data on the kinematics of faulting and block rotations, such as the surface faulting patterns in Homestead Valley described in the next section, we cannot eliminate certain block rotation models based on the inversion results alune. There is no relative vorticity associated with the San Andreas fault seismicity (Table 1).

The value of the parameter $D$ for the Big Bear aftershocks is 0.5 (Table 1), indicating a plane strain and consistent with a simple shearing deformation. The cluster of events southwest of the Big Bear earthquake similarly is characterized by $D=$ 0.5 . The value of $D$ for the cluster of aftershocks just north of the Frontal fault is 0.4 (slightly transtensional). We infer that these events occurred on a blind or unmapped fault in the footwall of the thrust and do not represent slip on the Frontal fault. The 0.7 values of $D$ obtained for the San Andreas fault region and for distributed seismicity in the San Bernardino Mountains east of the Big Bear rupture (Table 1) are moderately transpressional (dextral shear with north-south shortening accompanied by vertical crustal thickening). These 
transpressional values of $D$ are consistent with the deformation in the western Transverse Ranges, which accommodates north-south shortening in the vicinity of the contractional "big bend" in the trace of the San Andreas fault [Bird and Rosenstock, 1984; Weldon and Humphreys, 1986; Humphreys and Weldon, 1994].

\section{Inversion of Regional Coseismic Geodetic Data}

The strain inverted from geodetic data for cells that do not span the surface rupture or the buried faults reflects the gradient of strain away from the zone of discrete slip on the fault (Figure 2). If the far-field displacement is held fixed, a rightlateral displacement on the Landers rupture zone shears the volumes of rock both to the west of the fault and to the east of the fault in a left-lateral sense. The roughly NE-SW orientations of the maximum extension axes and the counterclockwise sense of rotation that we find directly to the west of the Landers surface rupture zone are consistent with such a geometry.

The varied strain orientations northwest of the Big Bear earthquake are more difficult to interpret. In this area, however, the resolution is very poor because the stations are widely spaced, the solutions for a number of the cells depend on one common central cell, and the regional strain probably is complicated by the superposition of effects from the Landers and the Big Bear events. Similar comments apply to the region south of the Pinto Mountain fault (Figure 2), although the geodetic surveys do not include the main shock displacement associated with the Joshua Tree earthquake.

\section{Background Seismicity (1981-1991) and Pre-1992 Ear thquakes}

The micropolar inversion of the Landers earthquake aftershocks shows that there are two major domains within the western and central Mojave block: (1) the San Bernardino Mountains, which are characterized by east-west extension and north-south contraction; and (2) the central Mojave block, which primarily is characterized by northwest-southeast extension and northeast-southwest contraction (Table 1 and Figure 3). We analyzed seismicity for the period 1981-1991 to compare the ostensible background or secular seismogenic deformation in the Mojave block with the 1992 Landers deformation. We divided the 1981-199l seismicity into two regions: one region associated with the San Bernardino Mountains west of the Johnson Valley fault, and a second region encompassing the central Mojave block that extends east of and includes the Johnson Valley fault. In addition, we inverted aftershock data from the 1975 Galway Lake earthquake and the 1979 Homestead Valley earthquake (Figure 6) to compare with 1992 aftershocks along the trend of the Landers rupture.

The results (Table 1) show that the distinctive orientations of the $d_{1}$ and $d_{3}$ principal strain rate axes for the two major domains are expressed in the background seismicity as well as the Landers aftershocks. Both the Galway Lake and Homestead Valley earthquake sequences, which occurred in the central Mojave block, generally are characterized by NW trending $d_{1}$. The kinematic parameters indicate that the background or secular seismogenic deformation of the central Mojave block is slightly transtensional $(D=0.4)$ with a positive relative vorticity $(W=0.4)$. For the San Bernardino Mountains, the kinematic parameters associated with the background seismicity indicate a general plane strain deformation ( $D=$ $0.5)$ and a minor negative relative vorticity $(W=-0.1)$ that may not be significantly different from zero (see Appendix B).

The secular geodetic strain in the Mojave block, as characterized by the orientation of $d_{1}$, has a deformation geometry similar to that expressed by the background seismicity. Based on analysis of geodetic data collected between 1934 and 1982, Sauber et al. [1994] reported that the orientation of $d_{1}$ for the region between the Helendale and Lenwood faults (Figure 1) is $90^{\circ} \pm 12^{\circ}$ and that the orientation of $d_{1}$ for the region between the Calico and Pisgah faults (Figure 1) is $107^{\circ} \pm 5^{\circ}$. These orientations are comparable to the orientations of $d_{1}=80^{\circ}$ for the San Bernardino Mountains and $d_{1}=109^{\circ}$ for the central Mojave block, respectively, obtained from inversion of background seismic $P$ and $T$ axes (Table 1). Although the secular geodetic strain shows a westto-east variation in the orientation of $d_{1}$ similar to that exhibited in the background seismicity, Sauber et al. [1994] find that the change in orientation at the latitude of $34^{\circ} 30^{\prime}$ occurs east of the Landers rupture, rather than to the west as we observe from analysis of the Landers earthquake aftershocks (Table 1). The secular shear strain in the Barstow area from trilateration studies performed during 1979-1989 is characterized by $d_{1}=102^{\circ} \pm 3^{\circ}$ [Savage et al., 1990], which is equivalent within measurement error to the orientation of $d_{1}=$ $103^{\circ}$ obtained from our inversion of Landers aftershocks from the Barstow area (Table 1).

Summarizing the results of this section, we conclude that the aftershock seismicity records substantially the same geometry of deformation as the coseismic geodetic data, that the regional pattern of deformation observed from both these data sets also appears in the background seismicity, and that this pattern of deformation also is characteristic of the secular geodetic strain of the Mojave block.

\section{Seismic and Structural Evidence for Coseismic Block Rotations Along the Kickapoo Fault}

The values of the relative vorticity parameter $W$ that result from the micropolar inversion of the seismic data (Table 1) suggest that significant block rotations occurred in a number of areas along the fault. Structural data gathered in Homestead Valley following the Landers earthquake provide independent data against which the implications of nonzero relative vorticity can be compared. The data show that the relative vorticity parameter contains nontrivial information about the kinematics of block rotations. Using the constraint provided by the value of $W$, we can infer a consistent kinematic model of block rotation for this region.

Detailed mapping in Homestead Valley revealed distinctive patterns of shearing at several scales that we assume reflects the kinematics of seismogenic faulting at depth. Johnson et al. [1993] characterized surface rupture along the major faults in this region as occurring primarily by distributed deformation within $50-200 \mathrm{~m}$ wide belts of shearing. The broad shear belts in turn consist of several smaller dextral shear zones ranging up to tens of meters in width. The shear belts are bounded by NW striking dextral faults or zones of north striking en echelon fractures, and they contain N-Sstriking extension fractures and NNE striking left-lateral shear fractures that typically are distributed across the entire shear zone. Johnson et al. [1993] interpreted kinematic indicators 
to show that the ground surface within the shear zones and the larger shear belts were subjected to a combination of dextral shear parallel to the walls of the zone, plus a component of dilation normal to the walls of the zone. Blocks bounded by the walls of the shear zones locally were rotated clockwise [Johnson et al., 1993].

Detailed mapping of the Johnson Valley fault near the southern end of the Kickapoo fault and of the Homestead Valley fault a few kilometers south of its intersection with the Kickapoo fault [Johnson et al., 1993], indicates that the width of the shear zones containing the rotating blocks ranges from a few meters to $40-60 \mathrm{~m}$. The long dimensions of the rotating blocks similarly range from a few meters to $40-60 \mathrm{~m}$ in length. The angle $(\alpha)$ between the generally N-S trending walls of the shear zones and the NE striking, block-bounding, sinistral faults, measured counterclockwise from the south, ranges between $140^{\circ}$ and $155^{\circ}$, with the majority of $\alpha$ ranging between $140^{\circ}$ and $150^{\circ}$ [see Johnson et al., 1993, Figure 7].

Shear zones and surface fractures with similar orientations were mapped at larger scales in Homestead Valley along the Kickapoo fault by Sowers et al. [1994]. In particular, the area near the junction of the Johnson Valley and Kickapoo faults is characterized by an approximately $1-\mathrm{km}$-wide zone of distributed shearing (Figure 9), including several shear zones similar to those described by Johnson et al. [1993]. In addition, at least one discontinous NE striking zone of surface fracturing extends across Homestead Valley between the Johnson Valley and Homestead Valley faults, approximately $2.5 \mathrm{~km}$ southeast of the Kickapoo fault (Figure 9). The angle $\alpha$ of this zone with respect to the N-S striking segment of the Johnson Valley fault south of the Kickapoo fault is approximately $150^{\circ}$.

The values of $W$ obtained from the micropolar inversion of aftershocks along the Kickapoo fault in Homestead Valley, and the surface mapping of the faults in that area, provide independent constraints that are consistent with the geometry of the blocks inferred from surface mapping and from which we can infer a block rotation model for the deformation in the seismogenic zone. Following Johnson et al. [1993], we assume that the style of surface deformation in Homestead Valley reflects the kinematics of seismogenic deformation at depth. We thus consider three general models (Figure 10). In the first model (Figure 10a), deformation within the shear zone is accommodated by distributed slip along the boundaries of lensoid blocks that are elongate parallel to the shear zone boundaries. In this model, the shape of the blocks may inhibit rotation about a vertical axis such that the microspin is either zero or at most is less than the macrospin, and consequently, the value of $W$ is less than zero. The second model is the pinned block model (Figure 10b), in which distributed shear is accommodated by the rotation of elongate blocks that behave as if they are fixed or "pinned" at their ends to the shear zone boundaries. Twiss et al. [1993] showed that the value of $W$ associated with this model is dependent on the angle $\alpha$ between the pinned blocks and the shear zone boundaries (Figure 10b). The third model is the floating block model (Figure 10c), which also assumes rotation of elongate blocks but does not require the ends of the blocks to be pinned to the shear zone boundaries. Instead, the kinematic moment of a block is assumed equal to that of the continuum displaced by the block. For the floating block model, Twiss et al. [1993] showed that $W$ is a function of the shape of the blocks and the angle $\alpha$ between the long axes of the blocks and the shear zone boundaries (Figure 10c). Note that for blocks oriented at $\alpha=$ $135^{\circ}$ or more to the shear zone boundaries, the pinned block model predicts positive values of $W$ (Figure 10b) and the floating block model predicts negative values of $W$ (Figure $10 c)$.

We reject the first kinematic model (Figure 10a) for block rotations in the vicinity of the Kickapoo fault because the pattern of surface faulting suggests elongate blocks oblique, rather than parallel to, the shear zone boundaries and because this model is characterized by negative values of $W$ in contrast to the positive values obtained from the micropolar inversion (Table 1). We note, however, that this model is one of the models that is consistent with shearing in the Johnson Valley fault zone south of the mainshock, where a negative value of $W$ was obtained from the inversion (Table 1).

The geometry of the two models involving rotation of elongate blocks at an angle to the shear zone boundaries (Figures $10 \mathrm{~b}$ and $10 \mathrm{c}$ ) is more similar to the pattern of surface faulting in the vicinity of the Kickapoo fault (Figure 9). Based on the detailed mapping by Johnson et al. [1993] and Sowers et al. [1994], discussed above, elongate, fault-bounded blocks along the Kickapoo fault in Homestead Valley generally make an angle $\alpha$ of between $138^{\circ}$ and $168^{\circ}$ with the shear zone boundaries. For these angles, the values of $W$ predicted by the pinned block model are approximately 0.2 to 0.4 , and values of $W$ predicted by the floating block model are $W<0$ (Figures $10 \mathrm{~b}$ and $10 \mathrm{c}$, respectively). The pinned block model clearly provides a better fit to the value $W=0.4$ obtained from the inversion (Table 1). We also note that the pinned block model predicts the value of $D$ for $\alpha$ between $138^{\circ}$ and $168^{\circ}$ to be approximately 0.45 , comparable to the value of $D$ that minimizes the error in the misfit of the inverse solution for the Kickapoo fault (see Appendix B). This value of $D$ implies that the deformation includes a small component of extension normal to the shear zone boundaries (transtensional deformation), which is consistent with the interpretation of Johnson et al. [1993] based on kinematic analysis of surface faulting. Of the three kinematic models, therefore, the pinned block model provides the best fit to the style of surface faulting in the vicinity of the Kickapoo fault and to the values of $D$ and $W$ obtained from the micropolar inversion (Table 1).

Comparison of the structural data with the values of the relative vorticity parameter $W$ from the seismic data thus lead us to conclude that the block geometry observed at the surface is consistent with the inferred values of $W$ and with a pinned block model of block rotation within the shear zone. These results support our hypothesis that block rotations can result in an asymmetric seismic moment tensor [Twiss et al., 1993], that the asymmetry is reflested in the pattern of seismic $P$ and $T$ axes and that it can be detected by a micropolar inversion of the focal mechanism solutions.

\section{Seismotectonics of the Eastern California Shear Zone}

Geodetic analysis of strain accumulation in the Mojave block between 19,34 and 1982 has delineated an approximately 60-km-wide zone of distributed deformation extending at least from the Helendale to the Pisgah faults (Figure 1) and approximately centered on the system of linked strike-slip faults that ruptured during the Landers earthquake [Sauber et al., 1994]. The integrated rate of northwest dextral shear across this zone is approximately $12 \mathrm{~mm} / \mathrm{yr}$, which accounts for 22 - 


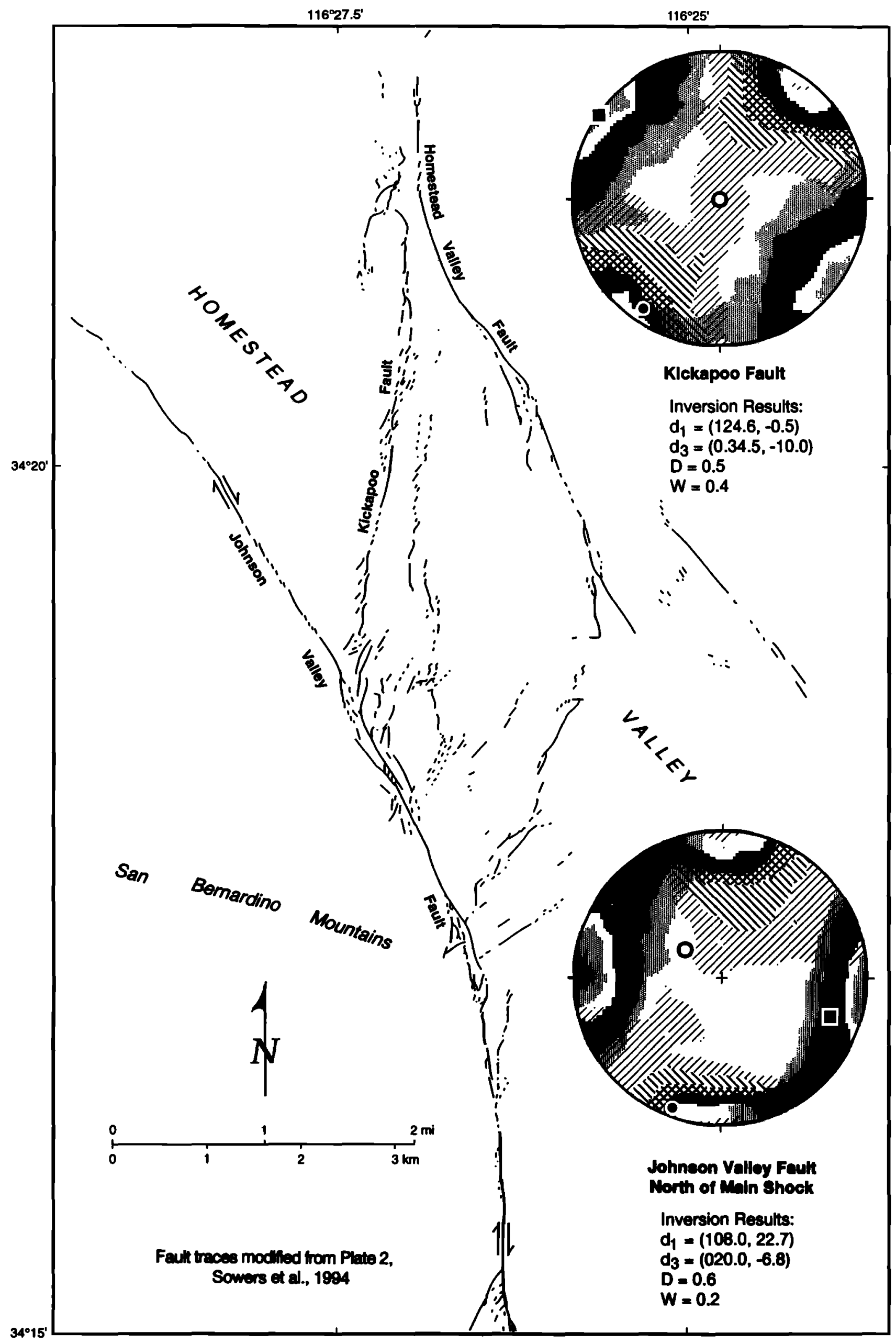


A

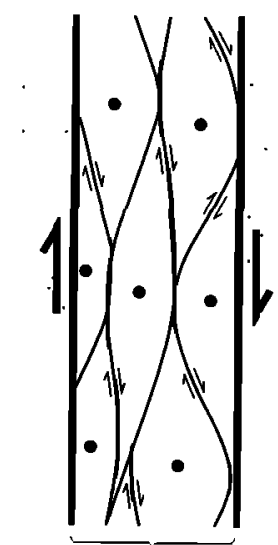

SHEAR ZONE

B

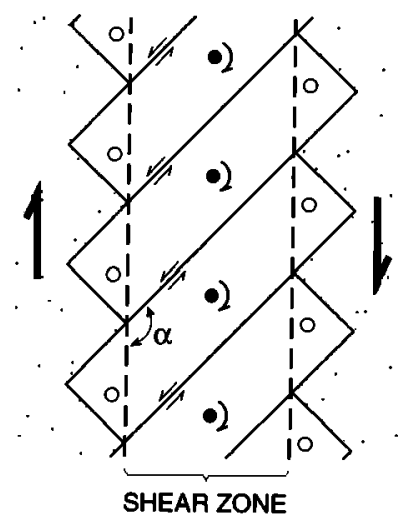

c

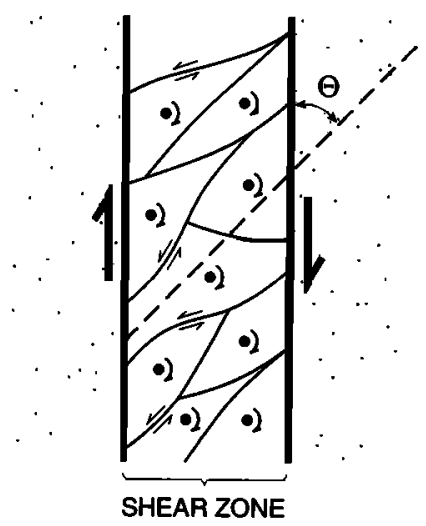

Microspin $\leq$ Macrospin, so $\mathrm{W} \leq \mathrm{O}$
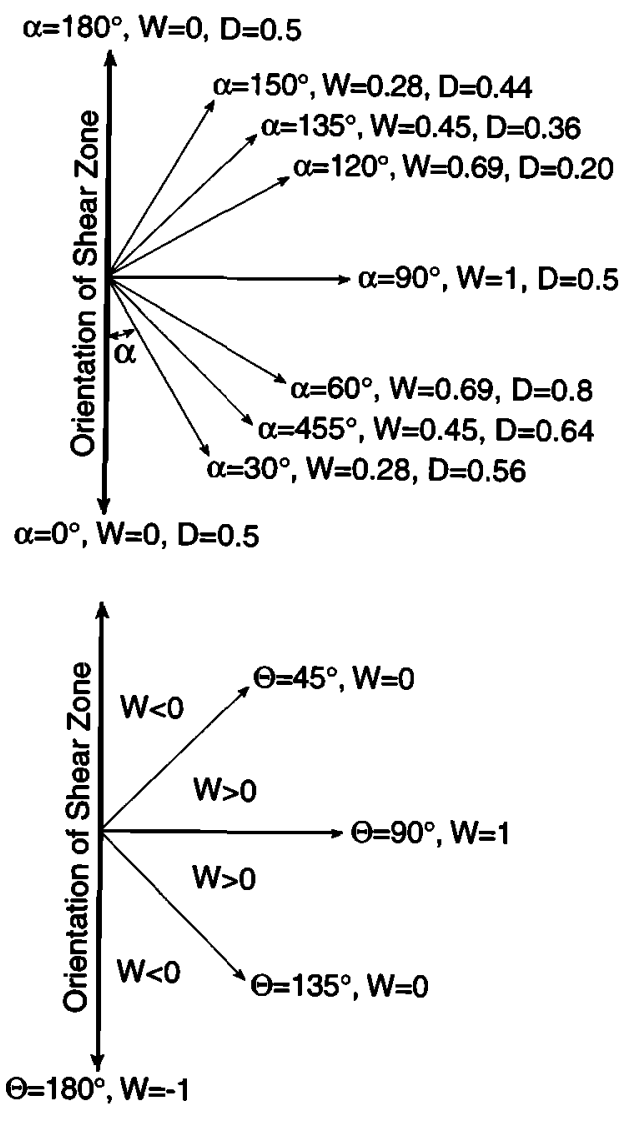

Figure 10. Generalized models for block rotations within shear zones. (a) Distributed shearing accommodated by slip along the margins of elongate blocks whose long axes are parallel or subparallel to the shear zone boundaries. The orientation of the blocks inhibits block rotation, so microspin $\leq$ macrospin and $W \leq 0$. (b) The pinned block model tor rotation of elongate blocks at an angle to the shear zone boundaries. Values of $W$ and $D$ are determined by the orientation of the long axes of the blocks relative to the shear zone boundaries (i.e., $\alpha$; see Twiss et al. [1993] for derivation of $W$ and $D$ as a function of $\alpha$ ). (c) The floating block model for rotation of elongate blocks within a shear zone. Values of $W$ are determined by the orientation of the long axes of the blocks relative to the shear zone boundaries (see Twiss et al. [1993] for derivation).

Figure 9 (opposite). Patterns of surface faulting in Homestead Valley associated with the Johnson Valley, Kickapoo and Homestead Valley faults (map data modified from Sowers et al. [1994]). 
25\% of the total Pacific/North American plate motion [Sauber et al., 1994]. This zone probably represents the modern locus of NW dextral shear deformation in the eastern California shear zone. Based on geologic relations, Dokka and Travis [1990] argued that the locus of shearing formerly was centered in the eastern Mojave block, but shifted westward to its present location in the central Mojave block in early to middle Quaternary time.

Lateral variations in the orientations of the seismogenic $d_{1}$ and $d_{3}$ axes inferred from inversion of aftershock focal mechanisms define orientational domain boundaries that coincide with the boundaries of the zone of northwest dextral shearing determined by geodetic methods. As illustrated in Figure $3, d_{1}$ and $d_{3}$ are oriented east-west and north-south, respectively, in the region southwest of the Helendale fault. Across a boundary that strikes approximately $\mathrm{N} 25^{\circ} \mathrm{W}$ between the Helendale and Lenwood faults, the trajectories of $d_{1}$ and $d_{3}$ change orientation toward NW-SE and NE-SW, respectively. The locus of this change appears to be well constrained by the inversions of the aftershock data from the western and southern Mojave block (Figure 3). Near the geodetically determined eastern boundary of northwest dextral shear in the eastern California shear zone, in the vicinity of the Pisgah fault, the inversion of focal mechanism data also gives orientations of $d_{1}$ and $d_{3}$ that are approximately northwestsoutheast and northeast-southwest, respectively (Table 1 and Figure 3). This one result is consistent with the geodetic measurements, but our data do not permit a constraint on the presence or location of an eastern boundary to the domain of NW-SE $d_{1}$ and NE-SW $d_{3}$ axes.

In an attempt to understand the significance of the orientations of the principal strain rate axes that we have found, we examine two simple models, which are represented by the two sets of principal strain rate trajectories that we have sketched in Figures 11 and 12, respectively. Each set of trajectories has been drawn by eye to provide a reasonable fit to the principal axes we have inferred, but in regions where no data exist, such as north of the Manix fault and east-northeast of the Pisgah fault, the trajectory orientations are strictly assumptions based on the characteristics of the model rather than constraints provided by data. For the first model, the different orientational domains of the principal axes are interpreted as a characteristic and stable feature that distinguishes the deformation geometry in the eastern California shear zone from that in adjacent areas (Figure 11). For the second model, the domain of NW-SE $d_{1}$ axes is interpreted as a transient feature associated with the rotation of principal stress and elastic strain axes associated with strain release by slip on the Landers rupture zone (Figure 12). We discuss each interpretation in tum below.

The first interpretation assumes that the NW-SE $d_{1}$ and the NE-SW $d_{3}$ orientations are a stable and characteristic feature of the eastern California shear zone. We assumed a shear zone of $60 \mathrm{~km}$ width, consistent with the width of the zone of dextral shear strain accumulation in the eastern California shear zone as determined by geodetic analysis [Sauber et al., 1994]. We further assumed that the strike of the shear zone is approximately $\mathrm{N} 25^{\circ} \mathrm{W}$ based on the trend of the boundary between the E-W $d_{1}$ domain and the NW-SE $d_{1}$ domain obtained from the inversion analysis (Figure 3 ). We required that the principal strain rate axes be at $45^{\circ}$ to the shear zone boundaries at the center of the zone, and we constructed smooth trajectories for the axes to connect the orientations that we have found both inside and outside the shear zone (Figure 11). The deformation geometry for dextral shearing across a $\mathrm{N} 25^{\circ} \mathrm{W}$ trending zone requires $d_{1}$ to be oriented at $110^{\circ}$ and $d_{3}$ to be oriented at $20^{\circ}$. Although there is local variation in the orientation of the principal strain rate axes within the NW trending zone, most of the best fit orientations of $d_{1}$ and $d_{3}$ lie within about $15^{\circ}$ of these model directions (Table 1). The one exception lies at the northern end of the Landers surface rupture, on the northern Camp Rock fault, and we would associate this deviation with a stress concentration and reorientation at the end of the rupture.

The simple model in Figure 11 is consistent with regional fault kinematics in the western and central Mojave block. Major northwest striking dextral faults in the eastern California shear zone such as the Calico, Emerson, and Lenwood faults generally are parallel to the $\mathrm{N} 25^{\circ} \mathrm{W}$ direction of macroscopic dextral shear. Given the deformation geometry of the eastern California shear zone, the orientations of the northeast striking Manix and Cady faults also are consistent with the observed sinistral shear sense of these structures [Dokka and Travis, 1990]. In addition, the model predicts that dextral faults in the western Mojave block should strike more westerly than dextral faults in the eastern California shear zone because $d_{1}$ trends east-west in this domain, rather than northwest-southeast. This prediction is consistent with the more westerly strike of the Helendale and Lockhart faults, which appear to be generally parallel to the direction of the maximum rate of dextral shear in the western Mojave block (Figure 11). The model in Figure 11 therefore appears to account for the variations in strike of major strike-slip faults in the western and central Mojave block noted by previous workers [Cummings, 1976; Nur et al., 1993].

The second interpretation (Figure 12) assumes the domain of NW-SE $d_{1}$ and NE-SW $d_{3}$ reflects a transient reorientation of the principal axes associated with strain release along a discontinuity in an elastic plate. Pollard and Segall [1987] considered theoretically the problem of a finite frictionless surface (an idealized fault) in an infinite elastic plate under stress, and they plotted the principal stress orientations around such a discontinuity. The frictionless boundary condition requires that the surface support no shear stess and thus that the principal stresses be normal and parallel to the fault at the fault plane. This model results in a $90^{\circ}$ discontinuity in orientation of the principal axes across the fault. If some degree of friction on the fault is permitted, the principal stresses at the fault surface maintain some inclined angle to the fault commensurate with the level of friction assumed, but a discontinuity in orientation still remains. For the ideal isotropic homogeneous elastic plate, we can associate exactly the principal axes of stress with the principal axes of infinitesimal strain, and we must then assume that these axes are the same as our principal axes of strain rate, which are in fact principal axes of incremental strain. Under these conditions, we can interpret the principal strain rate trajectories as equivalent to principal stress trajectories, and we have drawn the trajectories (Figure 12) so that they make a reasonable fit to the orientations we have determined and also preserve qualitatively the characteristics expected for a fault in an elastic plate based on the work by Pollard and Segall [1987, Figure 8.6C].

Although the elastic plate interpretation does account for the orientations of the principal axes, including the very different orientation at the northern end of the Landers surface 


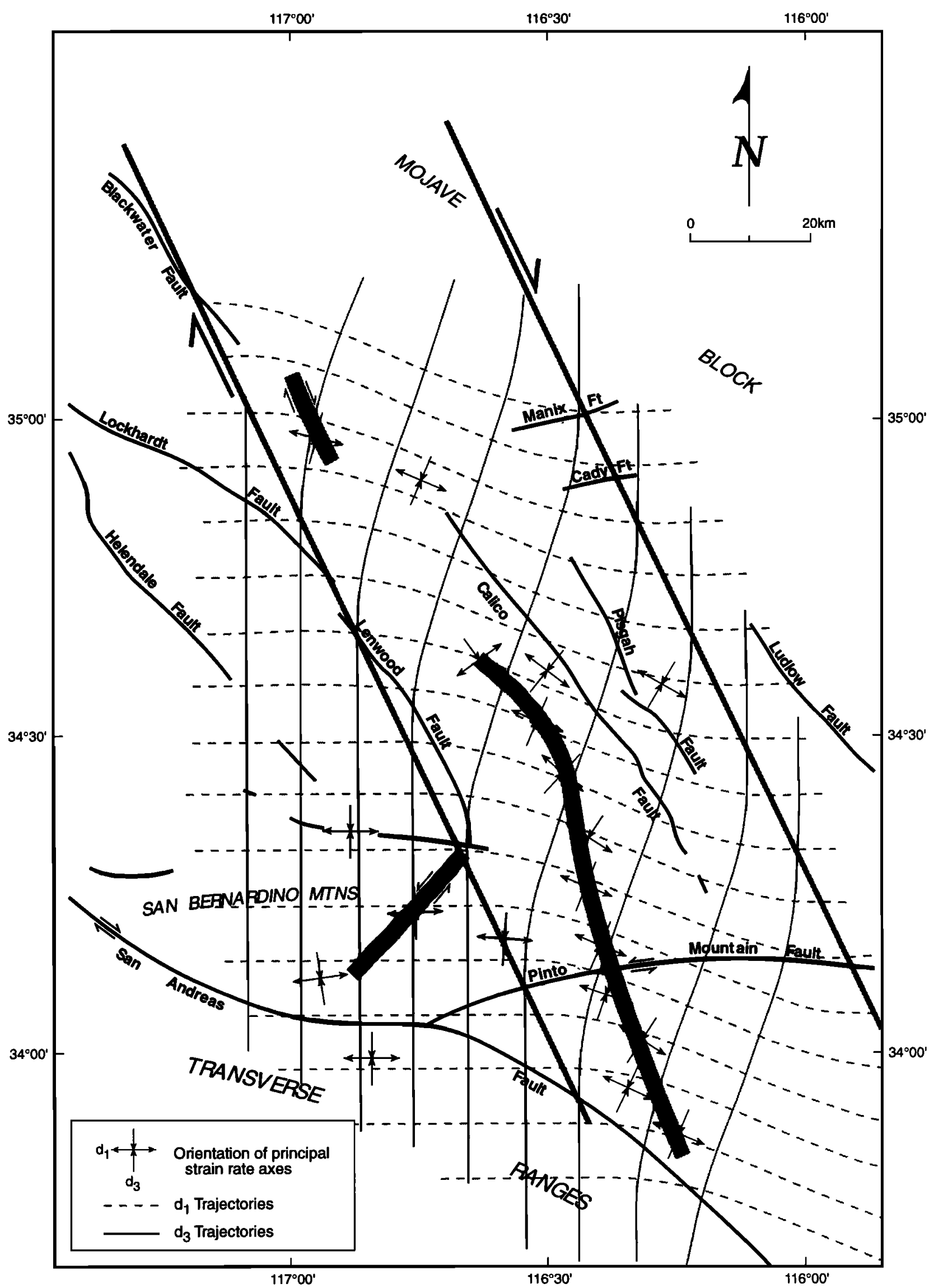

Figure 11. Principal strain rate trajectories drawn by eye to fit the focal mechanism inversion results and to illustrate the interpretation that the NW-SE orientation of $d_{1}$ axes in the central Mojave block reflects a stable, characteristic, and localized NW dextral shear in the eastern California shear zone [Sauber et al., 1994]. 


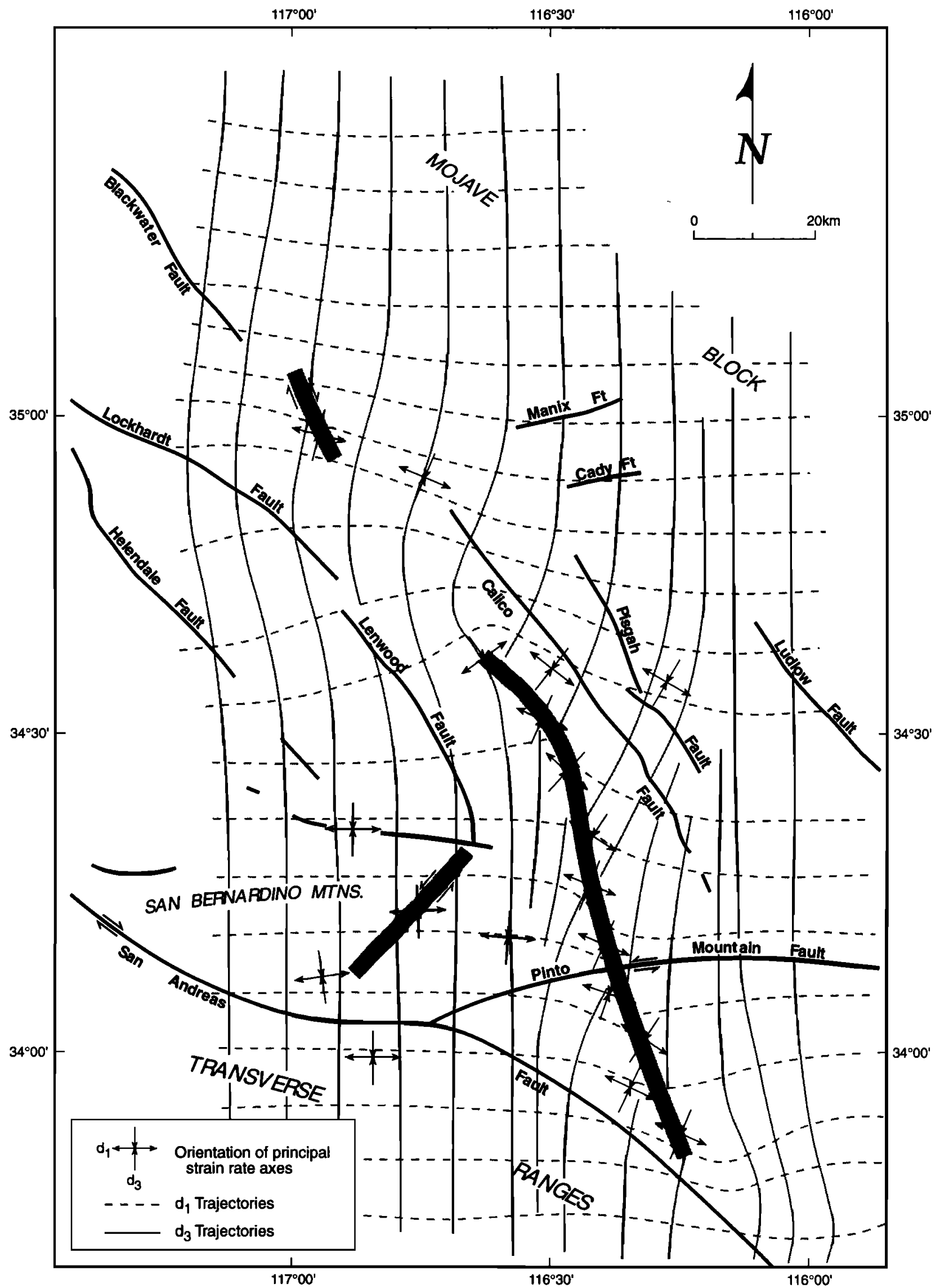

Figure 12. Principal strain rate trajectories drawn by eye to fit the focal mechanism inversion results and to be qualitatively similar to those from Pollard and Segall [1987, Figure 8.6C] for strain release by slip on a planar discontinuity in an elastic plate. 
rupture zone, we do not favor this interpretation for several reasons:

1. The seismogenic deformation from which we infer the orientations of the principal strain rate axes is a permanent inelastic deformation. In order to associate our results with the theoretical orientations for an elastic plate, we must argue that the aftershock deformation reflects the residual elastic deformation field that remains after the main slip event on the fault. In the theory, the fault zone appears as a discontinuity in the orientations of the principal axes, yet it is exactly from this theoretical discontinuity that we are obtaining the information from which we infer the principal axes. Thus upon careful reflection, the appropriate relationship between theory and observation is not obvious.

2. In successive quadrants around the fault, the $d_{1}$ axis and then the $d_{3}$ axis alternately should make a high angle with the fault plane; a sharp discontinuity in orientation occurs across the fault plane. We can fit our principal strain rate orientations and their variations along the fault with appropriately oriented trajectories only if we arbitrarily assume the inversion axes reflect the principal axes on the side of the fault where the maximum shortening direction $d_{3}$ makes the highest angle with the fault, although the one site at the northern end of the Landers surface rupture is an exception and fits the trajectory that makes the lowest angle with the fault. There seems no good justification, however, for assuming that the seismogenic strain within the fault zone should be associated with principal axes on one side of the fault or the other.

3. If the elastic plate model is correct, the orientations of the principal stress axes are transient, being significantly different before and after the main slip event. In the simplest model, the axes before the slip event should have the same orientation throughout the plate as the far-field orientations after the slip. The rotation of the trajectories near the fault should only occur because of the release of strain by slip on the fault, although that simple model does not take acocunt of inhomogeneous slip on the fault itself or of interactions among neighboring faults [Stein et al., 1992; Harris and Simpson, 1992; King et al., 1994]. The inversions for the secular seismogenic principal strain rate axes in the Mojave block for the decade preceding the Landers earthquake, however, show the same orientations that we infer from the aftershock data following the main earthquake, indicating that these orientations are not a transient feature associated with the slip event. Also, the varying trajectories of the late Cenozoic strike-slip faults, discussed above, probably reflect stable and persistent differences in the deformation of the western and central Mojave block over a time span sufficient to allow integration of the faults into single, well-defined traces. We assume that this time span must include at least several of the most recent surface-rupturing events in the western and central Mojave block and thus at a minimum extends as far back as the late Pleistocene.

Based on these observations, we conclude that the elastic plate model does not provide an adequate explanation for the orientations of the principal strain rate axes and that the orientation domain boundaries in fact define a region of deformation that is unique to the eastern California shear zone. Furthermore, the observed coseismic deformation geometry in the eastern California shear zone generally is consistent with the NW dextral shear determined by geodetic analysis of secular deformation [Sauber et al., 1994]. Thus, we infer that the Landers earthquake aftershocks are sensitive indicators of lateral variations in the regional deformation field affecting the central and western Mojave block. These variations define two domains, the San Bernardino Mountains and the eastern California shear zone, that are characterized by significantly different and stable deformation geometries.

We assume that if the deformation is averaged at a scale appropriate to provide a continuum description, the vertical gradients through the lithosphere in the horizontal components of velocity are small, so that the map of the surface strain rate trajectories (Figure 11) can be interpreted as an approximate reflection of the ductile deformation of the lower crust and upper mantle. We therefore interpret our results as indicating a transfer of Pacific/North American plate motion from the San Andreas system eastward to the Walker Lane belt, consistent with the interpretation of Sauber et al. [1994] that brittle deformation on multiple discrete faults in the eastern California shear zone is accommodated by distributed ductile deformation at depth.

\section{Discussion}

Our results suggest that the aftershocks of the Landers earthquake record a pattern of principal strain rate axis orientations in the eastern California shear zone that is characteristic of the zone and markedly different from the principal axis orientations in the surrounding crust (Figure 11). This pattern is characteristic of times that precede, are coeval with, and follow the Landers earthquake, and fault orientations in the region indicate that it has persisted at least for tens of thousands of years.

This result therefore indicates that the deformation recorded by the aftershocks is consistent with the ongoing deformation pattern of the whole region, as well as with the deformation associated with the mainshock. In particular, the aftershock deformation does not reflect highly reoriented residual stresses near a fault on which the stress drop has been essentially complete, and it is inconsistent with elastic rebound following dynamic overshoot of fault displacement during the main rupture event.

The data therefore suggest that there is a ductile component to the deformation that is not accounted for in strictly elastic plate models (we use the term "ductile" rather than "viscous" to avoid the implication that the material behavior is necessarily describable by a linear constitutive equation). It seems possible that the crust itself behaves like a ductile-elastic material rather than a strictly elastic one. Alternatively, the deformation in an upper brittle-elastic crust may be localized by a coupling to a ductile-elastic shear zone in the lower crust and upper mantle. The stress released by failure in the brittleelastic crust may be transferred to a ductile-elastic material at depth; the ductile relaxation of the elastic component of strain in this layer over time then drives continued aftershock deformation in the overlying weakened brittle fault zone. Scholz (1990, section 5.2) has reviewed the work on various models of this nature. In either case, our data are consistent with such models and indicate a more complex mode of deformation than is represented by a strictly homogeneous isotropic elastic plate.

Recent models used to calculate the variations in stress on adjacent faults due to the Landers rupture [Stein et al., 1992; Harris and Simpson, 1992; King et al., 1994] assume the Landers fault is a discontinuity in an otherwise homogeneous 
isotropic elastic plate subjected to boundary conditions consisting of uniform loads along its vertical edges. With these boundary conditions, a long-lived shearing in a restricted zone of strike-slip faulting such as the eastern California shear zone could develop only if a mechanical discontinuity existed at the boundaries of the shear zone that separated weaker material in the zone from stronger material outside, a departure from the assumption of homogeneity. Alternatively, the localized shearing in the brittle-elastic crust could occur if it were driven by a ductile shear zone beneath the horizontal lower boundary of the brittle-elastic plate, as suggested above, which implies different boundary conditions from those assumed.

The incompatibility between our results and these models used to calculate stresses on faults in the crust suggests the need for more complex models in evaluating the current state of crustal faults, as well as caution in interpreting the results of existing calculations.

In its current implementation, our inverse algorithm cannot evaluate the statistical significance of the inverse solutions for the parameters of the micropolar deformation model. This is an obvious deficiency that we are currently working to overcome (see Appendix A). Lacking a statistical measure of significance, we have resorted to comparing our results with independent observational data. The extent to which a theory is consistent or inconsistent with the physical world is, after all, the ultimate test of its validity, regardless of statistical calculations. The results for $D$ from the northern Johnson Valley fault, the Kickapoo fault, the San Andreas fault, and the San Bernardino Mountains are consistent with the independently known geometry of deformation in these regions. The results for $W$ from the Kickapoo fault are also consistent with the observed fault block geometry and fault kinematics observed at the surface rupture of that fault. Thus we conclude that despite the present lack of statistical measures of significance, the correspondence of our micropolar inverse solutions with independent evidence where it is available indicates that the inverse solutions are providing meaningful information about fault kinematics. Because it includes the kinematic effects of block rotations, we conclude that the inversion based on a micropolar model of deformation is more detailed and complete than that provided by other inverse methods.

\section{Conclusions}

We summarize our conclusions based on our analysis of the seismic and geodetic data associated with the Landers earthquake as well as the secular seismic and geodetic data from the Mojave block in the following points:

1. Aftershocks to the Landers earthquake accommodate a deformation geometry similar to that of the main rupture and do not reflect either the elastic rebound of the faults or the effects of the residual stresses that would remain after a nearcomplete stress drop on the fault. This conclusion is supported by the similarity between the orientations of the principal strain rate axes obtained from the micropolar inversion of the aftershock focal mechanisms and the principal strain axes obtained from inversion of the geodetically measured coseismic displacements across the rupture zone.

2. The value of the deformation rate parameter $D$ obtained from the micropolar inversion of focal mechanism data provides a reliable index to the relative magnitudes of the principal strain rates for the local tectonic deformation. Where these values can be checked, such as on the northern Johnson Valley fault, the Kickapoo fault, the San Andreas fault, and in the San Bernardino Mountains, the geologically observed plane strain, transpression, or transtension is consistent with the value of $D$.

3 . The nonzero values of the relative vorticity parameter $W$ indicate rigid block rotation within seismogenic shear zones at depth. Inversion of aftershock data from the northern Johnson Valley and Kickapoo areas gives values of $W$ that are consistent with the observations from surface mapping of fault block shapes, orientations, and rotations. These surface data and $W$ constrain the models of block rotation that are possible, and specifically they are consistent with a pinned block model for block rotation in the shear zone. These results support our hypothesis [Twiss et al., 1993] that coseismic block rotations have an observable effect on focal mechanism solutions.

4. The nonzero values of the relative vorticity parameter $W$ imply that in general, an asymmetric seismic moment tensor provides the best fit to the deformation within the seismogenic shear zones. This information about the relative vorticity, which is contained in the antisymmetric part of the seismic moment tensor, cannot be recovered by inverting aftershock focal mechanism data for a (symmetric) stress tensor or by summing the local symmetric seismic moment tensors. The micropolar model for inverting the aftershock focal mechanisms therefore leads to a more complete description of the distributed deformation within seismogenic shear zones.

5. The deformation geometry in the eastern California shear zone is distinct from that in the adjacent western Mojave block, and this difference reflects a fundamental characteristic of the distribution of plate motions in the lithosphere. This conclusion is supported by the agreement in orientation of the principal strain or strain rate axes obtained from the Landers aftershock focal mechanism solutions, the geodetically measured coseismic displacements, the focal mechanism solutions for the background seismicity in the Mojave block, and the geodetically determined secular displacements in the region. Our results support the hypothesis that aftershocks and microseismicity can be used to evaluate and map the seismogenic deformation field, and that the seismogenic deformation reflects the regional tectonics. Specifically, the Landers earthquake aftershocks delineate spatial variations in the orientations of the principal strain rate axes that are consistent with the concentration of NW dextral shear in the eastern California shear zone [Dokka and Travis, 1990; Sauber et al., 1994].

\section{Appendix A: Inversion Scheme}

Our method of inversion uses a five-parameter grid search algorithm (PTGRDSRCH) to find a best fit solution to the seismic focal mechanism data. For each model in the grid, we calculate the mean misfit between the observed axes $P_{0}$ and $T_{0}$ and the best fit model axes $P$ and $T$ for each focal mechanism in the data set, and we search the grid for the model that minimizes the misfit. We do not assume that either the shear plane or the slip direction is known exactly, so error in the orientations of both the observed slip plane and the observed slip direction are assumed in searching for the best fit. 
The observed unit vectors $P_{0}$ and $T_{0}$ can be used to define an orthogonal triad of data unit vectors $b_{\alpha}(\alpha=1: 3)$

$$
b_{1}=T_{0}, \quad b_{2}=P_{0} \otimes T_{0}, \quad b_{3}=P_{0},
$$

where the operation in the middle equation is the vector, or cross, product. These axes in turn can be expressed in terms of the unit normal $\eta_{0}$ and the slip direction unit vector $v_{0}$ for each of the two possible nodal planes (equation (15)). For a particular deformation model, we can define a similar triad of model unit vectors $m_{\alpha}(\alpha=1: 3)$

$$
m_{1}=T, \quad m_{2}=P \otimes T, \quad m_{3}=P .
$$

The orientations of these vectors are determined by the orientation of the model shear plane unit normal $\eta$ and the slip direction unit vector $v$ in that plane, where $v$ is determined by $\eta$ and the five parameters that characterize the deformation model (equations (6)-(13)). Thus the $b_{\alpha}$ are known quantities from the data, and the $m_{\alpha}$ are determined as a function of the shear plane normal $\eta$ and parameters for the specific deformation model. The three vectors in each orthogonal unit triad $b_{\alpha}$ and $m_{\alpha}$ are not independent, because of the second equation in each of equations (A1) and (A2). Thus we need only concern ourselves with two of the vectors from each triad, and we will use $\alpha=1$ and 3 .

We wish to choose an appropriate function with which to measure the misfit between the two sets of orthogonal unit triads $b_{\alpha}$ and $m_{\alpha}$. To this end we assume that the probability distribution for each of the two independent vectors in each triad is a Fisher distribution [Fisher et al., 1987]. (Yin and Ranalli [1993] have taken a similar approach but assumed a Fisher and a von Mises distribution for the two vectors)

$$
\begin{aligned}
& f\left(b_{1}\right)=\frac{\kappa_{1}}{4 \pi \sinh \kappa_{1}} \exp \left[\kappa_{1} m_{1} \bullet b_{1}\right] \\
& f\left(b_{3}\right)=\frac{\kappa_{3}}{4 \pi \sinh \kappa_{3}} \exp \left[\kappa_{3} m_{3} \bullet b_{3}\right]
\end{aligned}
$$

where $\kappa_{\alpha}(\alpha=1,3)$ are the concentration factors. We use a Fisher distribution for vector quantities rather than a Bingham distribution for nondirectional axes because our $P$ and $T$ axes are defined by a specific relation (equation (15)), to the vectors $\eta$ and $v$, which therefore gives them significance as vector quantities. We use Fisher distributions for both vectors to avoid identifying either vector as unique in its contribution to the joint probability distribution function that we define below.

The joint probability distribution of two vectors is simply the product of the individual distributions. Assuming that the concentration factors are the same for both vectors,

$$
\kappa_{1}=\kappa_{3}=\kappa,
$$

the joint distribution is

$$
J\left(b_{1}, b_{3}\right)=\left[\frac{\kappa}{4 \pi \sinh \kappa}\right]^{2} \exp \left[\kappa\left(m_{1} \bullet b_{1}+m_{3} \bullet b_{3}\right)\right]
$$

The likelihood function for an entire data set $(i=1: N)$ is then just the product of the joint distributions for each data pair

$$
L\left(b_{1}^{(i)}, b_{3}^{(i)}\right)=\prod_{i=1}^{N} J^{(i)}\left(b_{1}^{(i)}, b_{3}^{(i)}\right)
$$

Assuming the concentration factor is the same for all data pairs, taking the natural logarithm of (A7), and using (A6) gives

$$
\ln L=2 N \ln \left[\frac{\kappa}{4 \pi \sinh \kappa}\right]+\kappa \sum_{t=1}^{N}\left[m_{1}^{(i)} \cdot b_{1}^{(t)}+m_{3}^{(t)} \bullet b_{3}^{(t)}\right] .
$$

We define a misfit angle $\mu^{(i)}$ by

$$
\cos \mu^{(i)} \equiv 0.5\left(m_{1}^{(i)} \cdot b_{1}^{(i)}+m_{3}^{(i)} \bullet b_{3}^{(i)}\right) .
$$

The misfit angle $\mu^{(i)}$ is the only quantity in (A8) that depends on the orientation $\eta$ of the model shear plane, so in finding the best fit shear planes for a given model, we should maximize $\cos \mu^{(i)}$ in order to maximize the likelihood function. To a first-order approximation, the angle $\mu^{(i)}$ can be shown to be the unique angle of rotation that rotates one orthogonal triad into coincidence with another, as we show below.

Given the two orthogonal triads $b_{\alpha}$ and $m_{\alpha}$ it is always possible, according to a theorem of Euler, to find a single rotation of angle $S$ about a single axis that rotates one triad into coincidence with the other [Angeles, 1988, equation 2.4.4d],

$$
\cos S=0.5\left(m_{a} \bullet b_{a}-1\right),
$$

where summation is understood over the repeated subscript. Using the second equations from (A1) and (A2), we find

$$
m_{2} \bullet b_{2}=\left(m_{3} \bullet b_{3}\right)\left(m_{1} \bullet b_{1}\right)-\left(m_{3} \cdot b_{1}\right)\left(m_{1} \bullet b_{3}\right) \text {. }
$$

Expanding the summation implied in (A10) and introducing (Al1) gives

$$
\begin{aligned}
& \cos S=0.5\left[m_{1} \cdot b_{1}+m_{3} \bullet b_{3}\right] \\
& +0.5\left[\left(m_{1} \bullet b_{1}\right)\left(m_{3} \bullet b_{3}\right)-1\right]-0.5\left[\left(m_{1} \bullet b_{3}\right)\left(m_{3} \bullet b_{1}\right)\right]
\end{aligned}
$$

When $S$ is small, we have the approximate relations

$$
\begin{array}{ll}
m_{1} \cdot b_{1} \cong 1 & m_{3} \bullet b_{3} \cong 1 \\
m_{1} \cdot b_{3} \cong 0 & m_{3} \cdot b_{1} \cong 0 .
\end{array}
$$

After introducing (A13) into (A12), the only nonzero term remaining is the first bracketed term in (A12). Comparing this result with (A9) shows that

$$
\cos \mu^{(i)} \cong \cos S^{(i)}
$$

and therefore that the best measure of misfit is approximately the cosine of the angle of rotation required to bring one orthogonal triad into coincidence with the other. We pick as the model unit vectors, the $P$ and $T$ vectors calculated for the nodal plane that gives the smallest misfit (largest $\cos S^{(i)}$ ) for a given model. We used the approximate measure of misfit rather than the exact measure because when we initially started the analysis, we made a guess as to the appropriate misfit function. Because subsequently we showed that the function we initially assumed is approximately correct, it seemed adequate for present purposes.

We solve the inverse problem by minimizing the mean misfit defined by

$$
\tilde{M} \equiv \frac{1}{N} \sum_{i=1}^{N}-\cos S^{(i)}
$$

where we introduce the negative sign to make a minimum out of the cosine function where it goes through a maximum at the 


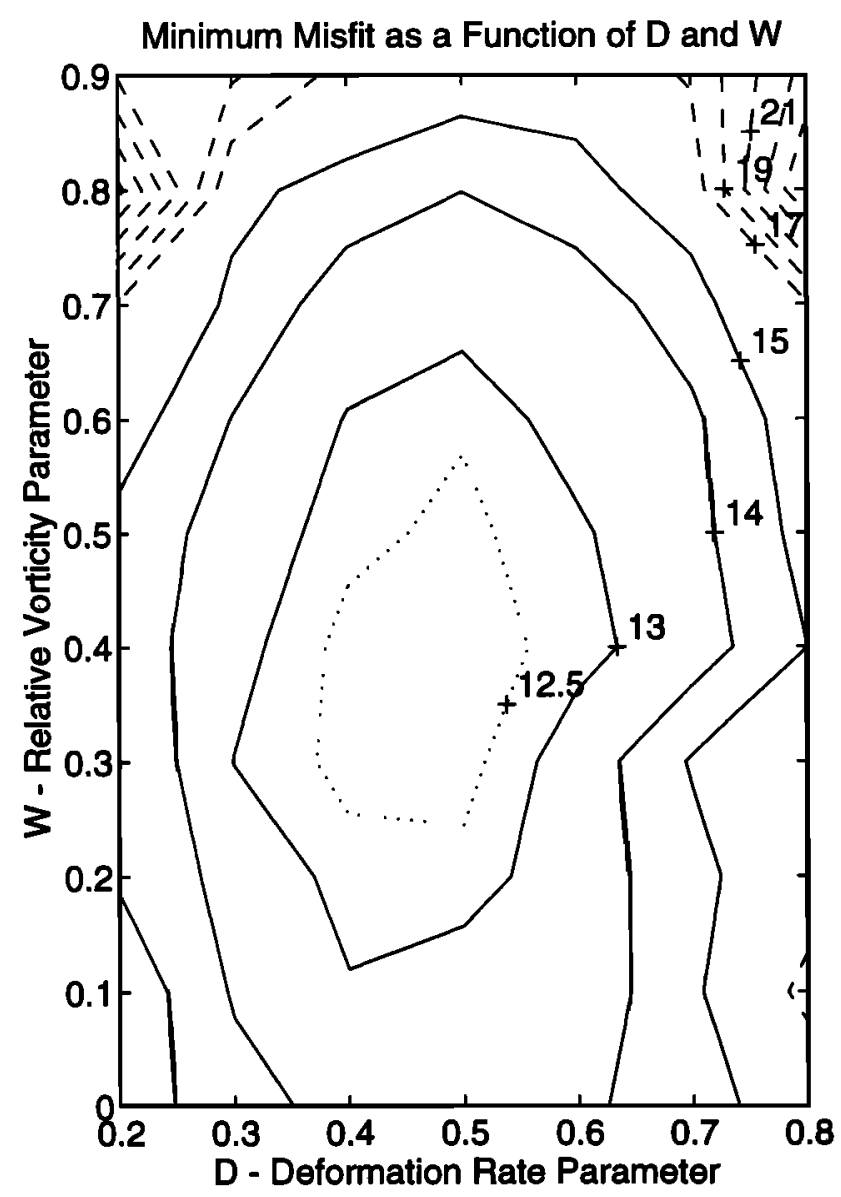

Figure B1a. Sensitivity analysis of the inversion results for the Kickapoo fault. Minimum model misfit, measured as $\min \left\{\cos ^{-1}[\right.$ mean $<\cos ($ misfit angle $\left.)>]\right\}$, and contoured as a function of $W$ and $D$. minimum value of $S^{(i)}$. We report the misfits for each data set as an angle $\bar{R}$ defined by

$$
\tilde{R} \equiv \cos ^{-1}(-\tilde{M})
$$

For each aftershock, $b_{\alpha}^{(i)}$ are known, and $m_{\alpha}^{(t)}$ are determined (within the ambiguity of two possible nodal planes) by the model shear plane normal $\eta^{(t)}$ and the slip direction $v^{(i)}$. Since from micropolar theory $v^{(t)}$ is itself a known function of $\eta^{(i)}$ and the parameters defining the micropolar deformation model (equations (6)-(13)), we have through (15) (A1), (A2), (A10), and (A15) an analytic function that relates the misfit $\vec{M}$ to the orientation of the model shear plane normals $\eta^{(t)}$ and to the characteristic parameters for the deformation model.

We use a conjugate gradient technique [Press et al., 1990, section 10.6] to find the best fit shear plane to each nodal plane for the particular deformation model. Our definition of the misfit between model and data is most similar to that used by Gephart [1990], who also permits error in both the shear plane orientation and the slip direction orientation. Gephart, however, minimizes the mean of his misfit angles; our measure of misfit $\tilde{M}$ (equation (A15)) has better statistical justification. The angle $\tilde{R}$ in (A16) is an angle that is larger, generally by a few degrees, than the mean of our misfit angles $S(i)$.

In searching for the best model to fit the data, we adopt as a starting point for the orientations of the principal deformation rate axes $d_{3}$ and $d_{1}$, a pair of orthogonal axes that are located at or near the maxima for the $P_{0}$ and $T_{0}$ axes, respectively, on Kamb-contoured plots. We use initial values of $D=0.5$ and $W$ $=0$. In general, we have not searched the entire grid systematically because of the large amounts of computer time that would be required. Instead, we generally search a swath around the path that leads from the starting model to the final solution, decreasing the size of the grid increments and

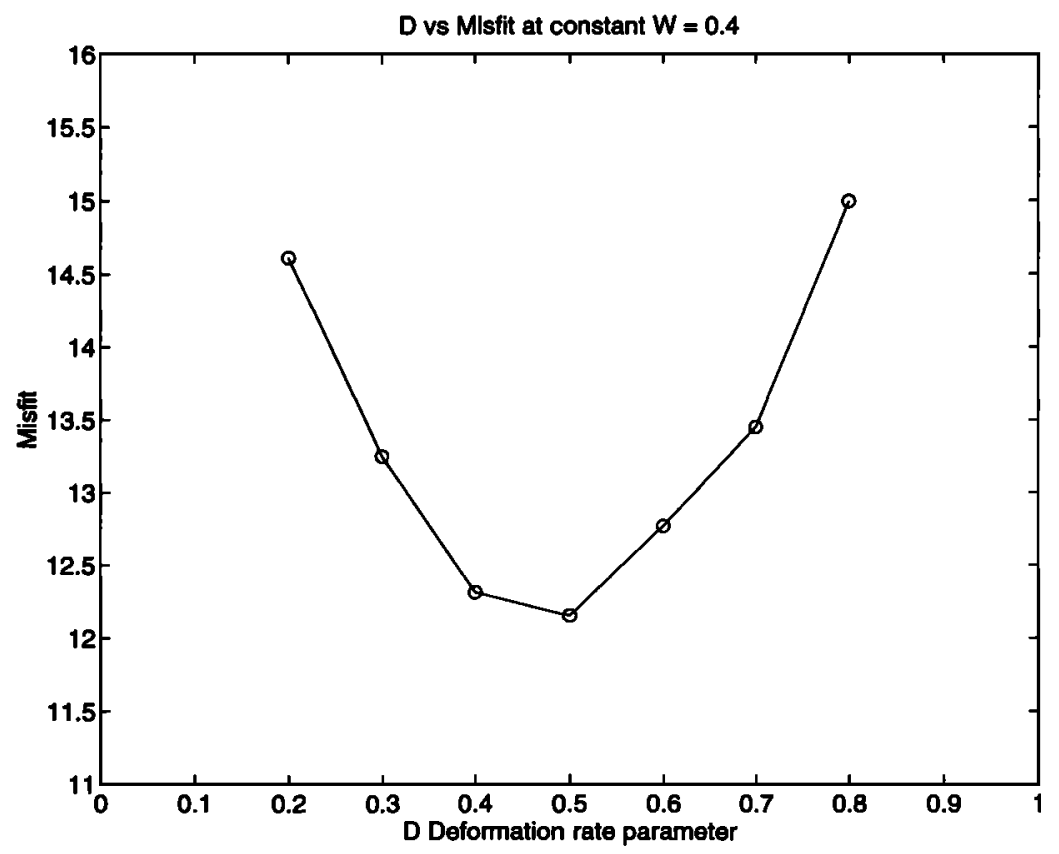

Figure B1b. Minimum model misfit as a function of $D$ (constant $W=0.4$ ). 


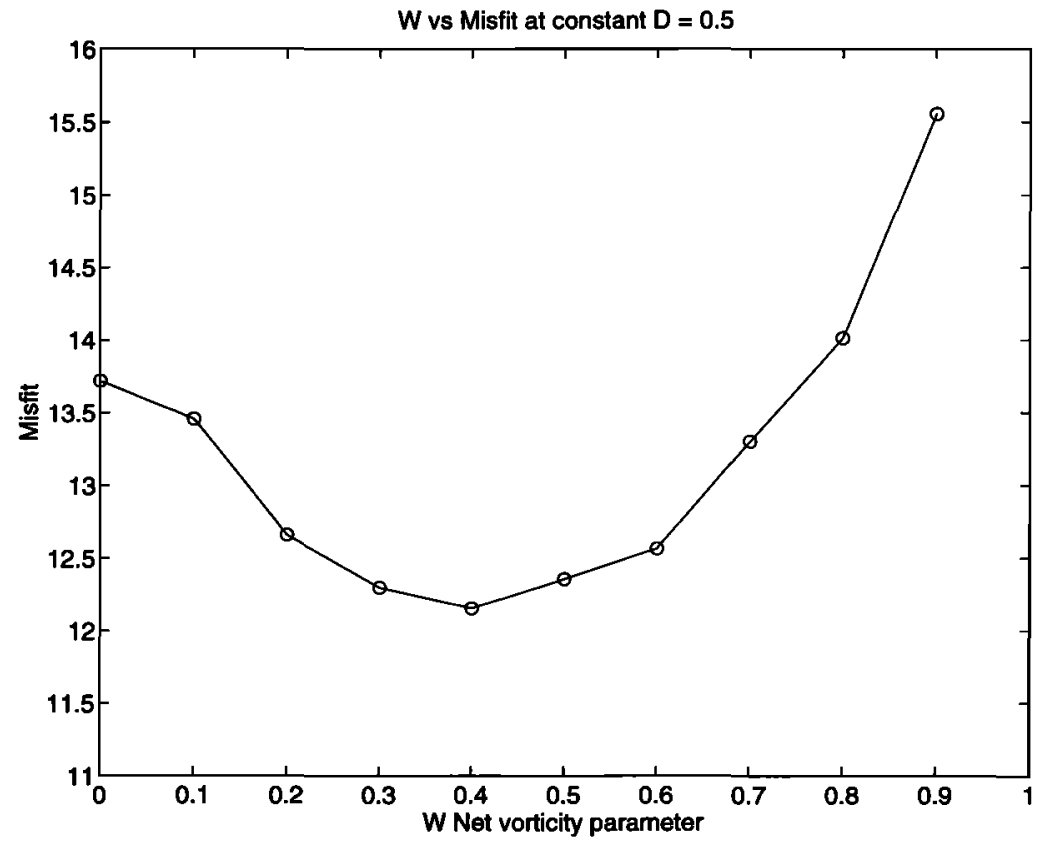

Figure B1c. Minimum model misfit as a function of $W$ (constant $D=0.5$ ).

searching a range of $D$ and $W$, as we approach the minimum. We ensure that the minimum is bracketed for all parameters in the grid search.

\section{Appendix B: Sensitivity Analysis of the Inversion Results}

The search strategy we employ does not permit us to determine rigorous statistical confidence limits for the characteristics of the deformation that we determine by inverting the seismic focal mechanism data. We have, however, done a sensitivity analysis for the inversion of aftershock data for the Kickapoo fault segment to demonstrate the effects on the misfit of varying the different parameters individually. This analysis indicates that for these data the misfit surface is relatively smooth, that it does not contain false minima, that the orientations of the principal strain rate axes are well constrained, that the value of $D$ is fairly well constrained, and that the value of $W$ is less well constrained. This result is consistent with our intuitive expectation that the effect of the relative vorticity is most probably a correction to the dominant symetric part of the deformation represented by the orientations and relative magnitudes $(D)$ of the principal strain rates.

The results of this analysis are presented in Figures B1 and B2. Figure B1a shows the misfit contoured on a graph of $W$ versus $D$. For each $(W, D)$ pair in the range $(0 \leq W \leq 0.9)$ and $(0.2 \leq D \leq 0.8)$, we searched for the minimum misfit on a $5^{\circ}$ grid for $\pm 10^{\circ}$ around the best fit orientations of $d_{1}$ and $d_{3}$. We did not search negative values of $W$, since these are equivalent to the positive values except with the principal strain rate axes rotated $180^{\circ}$ about $d_{3}$. The misfit is plotted in degrees as values of $\tilde{R}$ (equation $A(16)$ ). The misfit forms a fairly broad depression that bottoms out near the best fit values of $W=0.4$, $D=0.45$.

Figures B1b and B1c show two cross sections through the minimum on this graph, one at constant $D=0.5$ and the other at constant $W=0.4$. It is clear that the minimum is defined by steeper slopes for $D$ than for $W$, which is consistent with our expectation that the information in the focal mechanisms is more sensitive to variations in the strain rate tensor than it is to variations in the relative vorticity. Nevertheless, the misfit as a function of $W$ forms a definite minimum that constrains $W$ and suggests that we can resolve values of $W$ to within about \pm 0.15 .

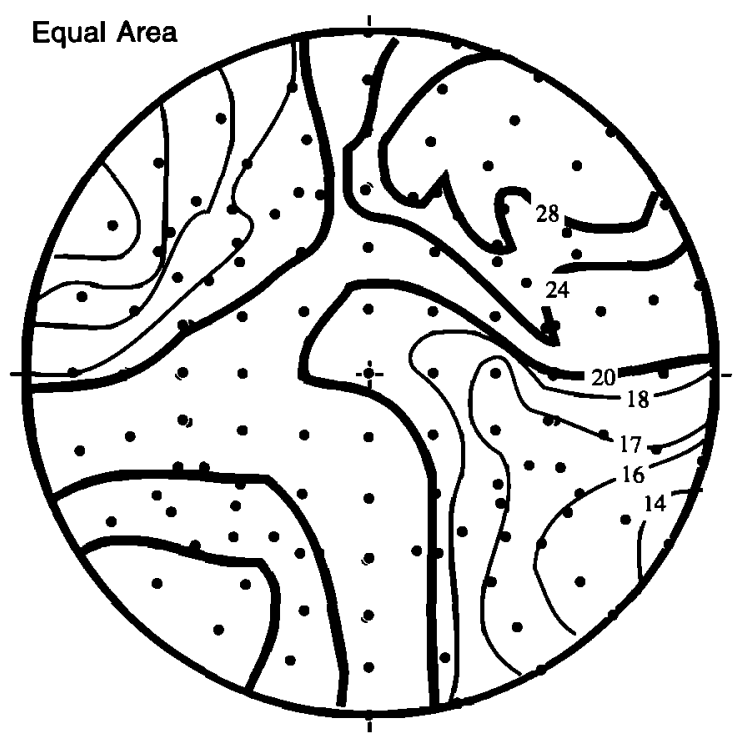

Refined Landers Fault Segment

Contours of minimum misfit as a function of $d(1)$ orientation $W=0.4$

$\mathrm{D}=0.5$

Best fit for $d(1)=(124.6,-0.5)$

Figure B2. Minimum model misfit as a function of the orientation of the maximum lengthening rate axis $d_{1}$ (constant $W=0.4$ and $D=0.5$ ). 
We also investigated the sensitivity of the misfit to the orientation of the maximum lengthening rate axis $d_{1}$ (Figure B2) for the Kickapoo fault segment. For this analysis, we held $W$ and $D$ constant at 0.4 and 0.5 , respectively, chose orientations of $d_{1}$ roughly on a $15^{\circ}$ grid that covers the lower plotting hemisphere, and for each $d_{1}$ searched all orientations of $d_{3}$ on a $15^{\circ}$ grid for the minimum misfit. The results of these calculations are shown in contours of $\tilde{R}$ evaluated for each orientation of $d_{1}$ on the lower plotting hemisphere. The misfit surface shows a well-defined minimum and is relatively smooth, confirming our impression from all our grid searches that the misfit surface is not complicated and that the minimum is robust. A finer grid that also included a search over values of $W$ and $D$ would undoubtedly have smoothed out some of the irregularities in this plot.

Acknowledgments. We thank the following people for their assistance in carrying out this study: Rick Allmendinger for the use of his program Stereonet 4.7-Ila with which we plotted our stereonet diagrams; Andrea Donnellan for her inversion program on which we based our program GPSTRN for calculating strains and rotations from geodetic data; and Jeff Freymueller for providing us the subroutines CONVCO and POLY44, which we used to calculate distances between geodetic stations from latitude/longitude data. Support for this research was provided to J.R.U. by a grant from the Department of Interior, U.S. Geological Survey (National Earthquake Hazards Reduction Program, contract 1434-94-G-2463); and to R.J.T. by a grant from the National Science Foundation (project EAR-9219633). The contents of this paper do not neccessarily represent the policy of the U.S. Geological Survey, however, and the endorsement of the federal government should not be assumed.

\section{References}

Angeles, J., Rational Kinematics, Springer Tracts Nat. Philos., vol. 34, edited by C. Truesdell, 137 pp., Springer-Verlag, New York, 1988.

Angelier, J., Determination of the mean principal directions of stresses for a given fault population, Tectonophysics, 56, T17-T26, 1979.

Argus, D.F., and R.G. Gordon, Current Sierra Nevada-North American motion from very long baseline interferometry: Implications for the kinematics of the western United States, Geology, 19, 1085-1088, 1991.

Aydin, A., and Z. Reches; Number and orientation of fault sets in the field and in experiments, Geology, 10, 107-112, 1982.

Bird, P., and R.W. Rosenstock, Kinematics of present crustal and mantle flow in southern California, Geol. Soc. Am. Bull., 95, 946-957, 1984.

Cummings, D., Theory of plasticity applied to faulting, Mojave desert, southern Califomia, Geol. Soc. Am. Bull., 87, 720-724, 1976.

Dixon, T.H., S. Robaudo, J. Lee, and M.C. Reheis, Constraints on present-day Basin and Range deformation from space geodesy, Tectonics, 14, 755-772, 1995.

Dokka, R.K., and C.J. Travis, Late Cenozoic strike-slip faulting in the Mojave desert, California, Tectonics, 9, 311-430, 1990.

Eringen, A.C., Simple micro-fluids, Int. J. Eng. Sci., 2, 205-217, 1964.

Eringen, A. C., Linear theory of micropolar elasticity, J. Math. Mech., 15, 909-924, 1966.

Eringen, A.C., Theory of micropolar fluids, J. Math. Mech., 16, 1-18, 1967.

Fisher, N.I., T. Lewis, and B.J.J. Embleton, Statistical Analysis of Spherical Data, Cambridge Univ. Press, New York, 1987.
Gephart, J. W., Stress and the direction of slip on fault planes, Tectonics, 9, 845-858, 1990.

Harris, R.A., and R.W. Simpson, Changes in static stress on southern California faults after the 1992 Landers earthquake, Nature, 360 , 251-254, 1992.

Hart, E.W., W.A. Bryant and J.A. Treiman, Surface faulting associated with the June 1992 Landers earthquake, Califomia, Calif. Geol., 46, 10-16, 1993.

Hauksson, E., State of stress from focal mechanisms before and after the 1992 Landers earthquake sequence, Bull.Seismol. Soc. Am. , 84, p. $917-934,1994$.

Hauksson, E., L.M. Jones, K. Hutton, and D. Eberhart-Phillips, The 1992 Landers earthquake sequence: Seismological observations, $J$. Geophys. Res., 98, 19,835-19,858, 1993.

Hudnut, K., et al., Co-seismic displacements of the 1992 Landers earthquake sequence, Bull.Seismol. Soc. Am., 84, 625-645, 1994.

Humphreys, E.D., and R.J. Weldon II, Defomation across the western United States: A local estimate of Pacific-North America transform deformation, J. Geophys. Res., 99, 19,975-20,010, 1994.

Johnson, A.M., R.W. Fleming, and K.M. Cruikshank, Broad belts of shear zones as the common form of surface rupture produced by the 28 June 1992 Landers, California, earthquake, U.S. Geol. Surv. Open File Rep.,93-348, 1993.

King, G.C.P., R.S. Stein, and J. Lin, Static stress changes and the triggering of earthquakes, Bull. Seismol. Soc. Am., 84, 935-953, 1994.

Kostrov, V.V., Seismic moment and energy of earthquakes, and seismic flow of rock, Izv. Acad. Sci. USSR Phys. Solid Earth, Engl. Transl., no. 1, 23-44, 1974.

Kranz. R.W., Multiple fault sets and three-dimensional strain: Theory and application, J. Struct. Geol., 10, 225-237, 1988.

Marrett, R., and R.W. Allmendinger, Kinematic analysis of fault-slip data, J. Struct. Geol., 12, 973-986, 1990.

Menke, W., Geophysical Data Analysis: Discrete Inverse Theory, Academic, San Diego, Calif., 1984.

Michael, A.J., Determination of stress from slip data: Faults and folds, $J$. Geophys. Res., 89, 11,517-11,526, 1984.

Nur, A., H. Ron, and G. Beroza, The Landers-Mojave earthquake line: A new fault system?, GSA Today, 3, 253-258, 1993.

Odé, H., Faulting as a velocity discontinuity in plastic deformation, in edited by D.T. Griggs and J. Handin, Rock Deformation, Mem. Geol. Soc. Am., 79, 293-321, 1960.

Oertel, G, The mechanics of faulting in clay experiments, Tectonophysics, 2, 343-393, 1965.

Pollard, D.D., and P. Segall, Theoretical displacements and stresses near fractures in rock: With applications to faults, joints, veins, dikes, and solution surfaces, in Fracture Mechanics of Rocks, edited by B.K. Atkinson, pp. 277-349, Academic, San Diego, Calif., 1987.

Press, W.H., B.P. Flannery, S.A. Teukolsky, and W.T. Vettering, Numerical Recipes, the Art of Scientitic Computing, New York, 702pp., Cambridge Univ. Press, 1990

Reches, Z., Analysis of faulting in three dimensional strain fields, Tectonophysics, 47, 109-129, 1978.

Reches, Z., Analysis of faulting in three dimensional strain fields, II, Theoretical analysis, Tectonophysics, 95, 133-156, 1983.

Reches, Z., and J. Dieterich, Faulting of rocks in three dimensional strain fields: I. Failure of rocks in polyaxial, servo-control experiments, Tectonophysics, 95, 111-132, 1983.

Sauber, J., W. Thatcher, S.C. Solomon, and M. Lisowski, Geodetic slip rate for the eastern California shear zone and recurrence time of Mojave desert earthquakes, Nature, 367, 264-266, 1994.

Savage, J.C., M. Lisowski and W.H. Prescott, An apparent shear zone trending north-northwest across the Mojave desert into Owens Valley, eastern California, Geophys. Res. Lett., 17, 2113-2116, 1990. 
Scholz, C.H., The Mechanics of Earthquakes and Faulting, Cambridge Univ. Press, New York, 1990.

Sowers, J.M., J.R. Unruh, W.R. Lettis and T.D. Rubin, Relationship of the Kickapoo fault to the Johnson Valley and Homestead Valley faults, San Bernardino County, CA, Bull.Seismol. Soc. Am., 84, 528536, 1994.

Stein, R.S., G.C.P. King, and J. Lin, Change in failure stess on the southern San Andreas fault system caused by the 1992 magnitude=7.4 Landers earthquake, Science, 258, 1328-1332, 1992.

Stewart, J.H., Tectonics of the Walker Lane belt, western Great Basin: Mesozoic and Cenozoic deformation in a zone of shear, in Metamorphism and Cause of Evolution of the Western United States, Rubey Volume 7, edited by W.G. Ernst, pp. 683-713. Prentice-Hall, Englewood Cliffs, N.J., 1988.

Twiss, R.J., and E.M. Moores, Structural Geology, W.H. Freeman, New York, 1992.

Twiss, R.J., G.M. Protzman, and S.D. Hurst, Theory of slickenline patterns based on the velocity gradient tensor and microrotation, Tectonophysics, 186, 215-239, 1991.

Twiss, R.J., B.J. Souter, and J.R. Unruh, The effect of block rotations on the global seismic moment tensor and patterns of seismic $P$ and $T$ axes, J. Geophys. Res., 98, 645-674, 1993.
Unruh, J.R., W.R. Lettis and J.M. Sowers, Kinematic interpretation of the 1992 Landers earthquake, Bull. Seismol. Soc. America , 84, 537546, 1994

Weldon, R., and G. Humphreys, A kinematic model of southern California, Tectonics, 5, 33-48, 1986.

Wright, L.A., Late Cenozoic fault patterns and stress fields in the western Great Basin and westward displacement of the Sierra Nevada block, Geology, 4, 489-494, 1976.

Yin, Z.-M., and G. Ranalli, Determination of tectonic stress field from fault slip data: Toward a probabilistic model, Geophys. Res., 98, 12,165-12,176, 1993.

E. Hauksson, Seismological Laboratory, California Institute of Technology, Mail Code 252-21, Pasadena, CA 91125

R. J. Twiss, Department of Geology, University of California, Davis, CA 95616.

J. R. Unruh, William Lettis \& Associates, Inc., 1777 Botelho Drive, Suite 262, Walnut Creek, CA 94596. (e-mail: wla@netcom.com)

(Received March 27, 1995; revised September 25, 1995; accepted September 29, 1995.) 